\title{
Assessment of Beef Quality Determinants Based on Consumer Preferences
}

\author{
Joseph Tenson Mwashiuya1', Samwel Victor Manyele², George Mwaluko \\ ${ }^{1}$ Department of Mechanical and Industrial Engineering, University of Dar es Salaam, Dar es Salaam, Tanzania \\ ${ }^{2}$ Department of Chemical and Mining Engineering, University of Dar es Salaam, Dar es Salaam, Tanzania \\ Email: joseftenson@yahoo.com, smanyele@udsm.ac.tz,mwalukogeorge@yahoo.com
}

How to cite this paper: Mwashiuya, J.T., Manyele, S.V. and Mwaluko, G. (2018) Assessment of Beef Quality Determinants Based on Consumer Preferences. Journal of Service Science and Management, 11, 657-690.

https://doi.org/10.4236/jssm.2018.116045

Received: October 18, 2018

Accepted: December 25, 2018

Published: December 28, 2018

Copyright $\odot 2018$ by authors and Scientific Research Publishing Inc. This work is licensed under the Creative Commons Attribution-NonCommercial International License (CC BY-NC 4.0). http://creativecommons.org/licenses/by-nc/4.0/

\begin{abstract}
This study presents the assessment of beef quality determination based on the consumer preferences, established in the beef retailing shops. The aim was to establish correlation between the customers' preferences and quality attribute cues affecting their preferences. Systematic review approach was used to identify studies connected with beef quality determination, leading to secondary data. The primary data on consumer preferences was collected from 208 and 98 customers in Dar es Salaam and Mbeya cities in Tanzania. Quality attribute cues that impact customer preference were collected using a Likert scale technique and analyzed by using Kruskal-Wallis one way ANOVA by ranks, after checking the reliability by multiple regression model. Tenderness, price, juiciness, breed's information and fat content were observed to be the five topmost overall ranked quality cues that impact customers' preferences. With respect to relative ranking, the highest relatively ranked beef quality cues in search, experience and credence attributes were price, tenderness and breed's information. Based on primary data, the assessed quality cues were positively accepted as the factors that influence consumers' preferences on butcher's location (73.5\% and $72.6 \%)$, personal relation with sellers $(69.4 \%$ and $69.7 \%)$, beef color (70.4\% and 70.2\%) and fat content (69.4\% and $69.2 \%)$ in Mbeya and Dar es Salaam, respectively, and noted to be very comparable between the cities. With exception of the photo of choice standard graded beef, the responses of customers in Mbeya were relatively higher than in Dar es Salaam, with type of cut and beef cleanliness being the two highest pointed quality cues.
\end{abstract}

\section{Keywords}

Beef Quality Determination, Customer Preferences, Photos of Standard Graded Beef, Quality Attribute Cues, Butcher Location, Beef Cleanliness, Beef Color, Beef Cut Type, Beef Fat, Beef Certification 


\section{Introduction}

Beef quality determinants are quality cues that are available in the selling outlet during inference making about beef by customers under the influence cultural and socio-economic diversity [1] [2] [3]. In this regards beef quality cues are described based on both inherent characteristics and element of acceptability. While in the former scenario, the beef quality is determined based available standards, the latter one includes customers' optimum needs and motivation [2]. The customers' optimum need and motivation that are also referred as subjective likings of individual customers are assessed by their satisfaction with quality attributes cues after purchase. This satisfaction is always recognized as utility, i.e., the property of beef that enables it to satisfy human wants [1].

Customer preferences in beef determination are described based on the meaning of quality as per economic point of view [1]. In this regards, the quality perspective is classified into user of beef and beef as a product point of views. While the former view includes attributes that provide the greatest satisfaction to a specified user, the latter one involves inherent characteristics of beef [1]. Therefore, these classes of quality perceptions are considered as the source of confusion as different customers have different views on a particular product [4] [3]. On the other hand, while the user based approach considers differences in demand and or expectations among individual, the lacking of optimum state of beef quality is felt [4].

Consumer decision making in beef determination involves three main scenarios that were described based on quality attributes that are evaluated by quality cues across search, experience and credence qualities [5] [6] [7]. While search quality involves quality attribute cues that are available at purchasing point, experience quality (eating quality) includes quality attribute cues which are available in use or with consumption [1] [6]. Credence quality on the other hand involves quality attributes with of concerns for consumers but where no cues are accessible in the process of buying or consuming [6]. Beef quality determination is influenced by the combination of quality attributes with respect to the consumers' need as shown in Table 1.

In spite of the fact that beef is the third most widely consumed meat in the world [7] [8] [9], it is difficult to match consumer preferences and quality attributes cues at purchasing points [10]. The mentioned difficulty is described

Table 1. Beef quality attributes cues arranged according to the means in which they are used to evaluate beef quality.

\begin{tabular}{|c|c|c|c|}
\hline & Search quality & Experience quality & Credence quality \\
\hline $\begin{array}{l}\text { Intrinsic } \\
\text { cues }\end{array}$ & $\begin{array}{l}\text { Beef color, leanness, } \\
\text { marbling, type of cuts, } \\
\text { fat, beef cleanliness }\end{array}$ & $\begin{array}{l}\text { Beef color, tenderness, } \\
\text { juiciness, flavor, beef cleanliness }\end{array}$ & Freshness \\
\hline $\begin{array}{l}\text { Extrinsic } \\
\text { cues }\end{array}$ & $\begin{array}{l}\text { Price, Butcher's } \\
\text { location, relation }\end{array}$ & - & $\begin{array}{l}\text { Breed's information, } \\
\text { certification, fat }\end{array}$ \\
\hline
\end{tabular}


based on the eating type of quality that is noted as the most important aspect of beef quality that include overall satisfaction and a function of combined effects of tenderness, juiciness and flavor. Beef quality determination is too complex to appropriately decide as to whether beef in the retailing shops is suitable or not [11] [12]. The magnitude of the noted complexity is high in many countries and this is explained based on two main factors, i.e., availability of food specifications specifically on unbranded beef and the knowledge of matching consumer preferences in beef and quality attribute cues at purchasing points [6].

In the past, it was argued that food quality specifications are either absent or available but too stringent to be enforced in many countries [12]. This is a common characteristic in many developing countries where the return of the resources for appropriate beef production is relatively low, due to low purchasing power among the consumers compared to the developed countries [9]. The cost involved on feeding and appropriate management of pre-slaughters was also reported as another reason for the raised argument for not enforcing the food quality specification [12]. The consequence of this non-compliance to the established technical requirements is consumption of low quality beef from old and poorly conditioned cattle in many developing countries [9] [12]. This scenario was described based on lacking of the means and or difficultness on confirming of the search (expectation) and experience aspects of quality during the beef quality determination at the purchasing point. In connection to this fact, beef quality determination is associated with the absence of technique that is suitable (rapid, accurate and precise) enough to adopt the commercial situation [7] [10]. This is noted as the main challenge within the meat sector particularly on deciding both what to measure and how to measure in the processed product [6]. Therefore, it was generally observed that non-compliant to the technical food requirements and lacking of the self-explanatory framework that is both consistent and meets the stakeholders' expectation [12] [13] [14] is a problem that need was addressed in this study.

Generally, information and data connected to beef quality was collected through observation by using checklists and beef quality photo as guiding tool. Checklists and beef quality guiding tool were designed based on the identified gap from attention made by beef sellers to the customers in retailing shop as indicated in literature [15]. The whole information was conceptualized in a beef quality mapping schematic diagram, as shown in Figure 1. The designing was targeting on capturing beef quality impacting parameters as per pre-description mode in beef retailing. The designed checklists were available for not only observing the reality in field, but retrieving technical requirement information on beef quality within the meat sector.

In this study, the identified problem of matching beef quality cues and customers preferences on beef suitability was addressed by testing three main hypotheses. These hypotheses were established based on the gaps identified from the reviewed approaches on determination of beef quality in the retailing shops. The first hypothesis was testing as to whether the reviewed search beef quality 


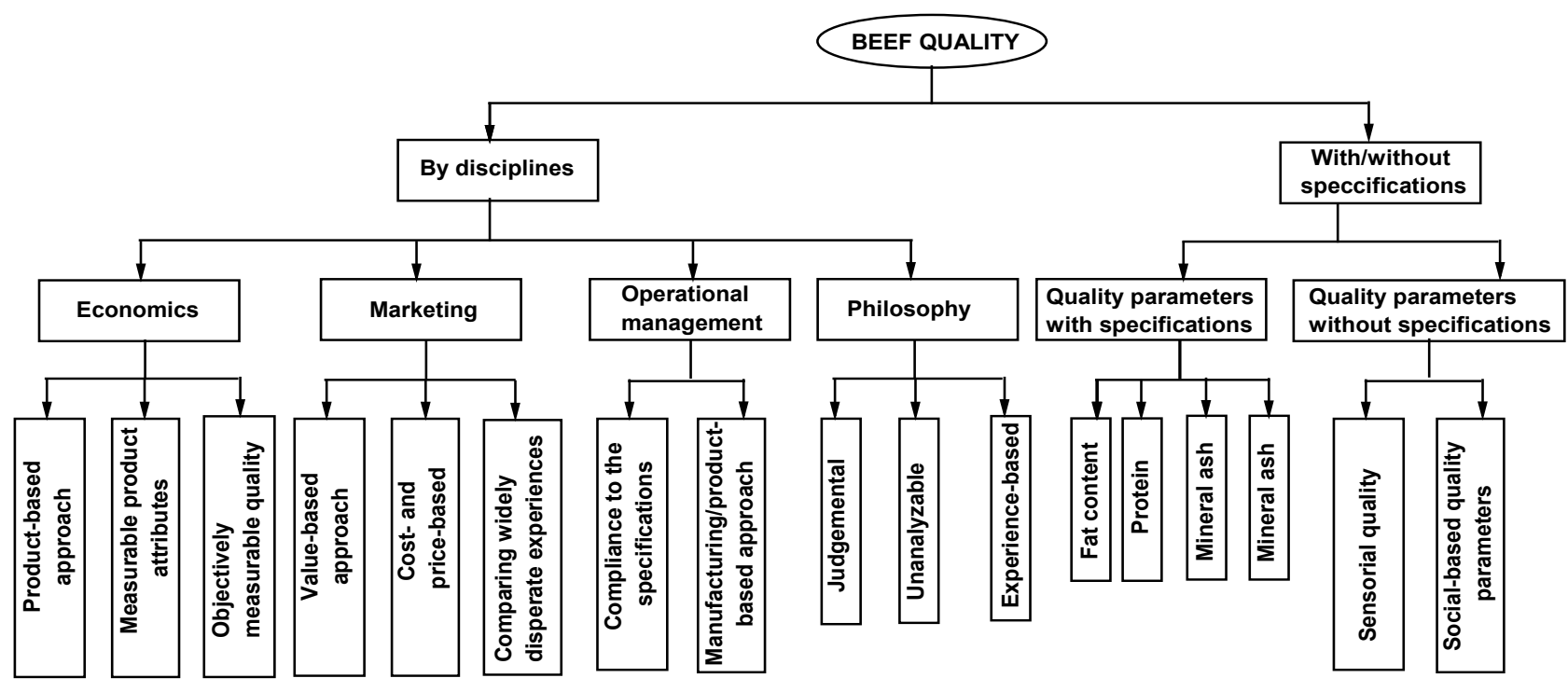

Figure 1. Conceptualized schematic mapping indicating the disciplines used in describing beef quality and quality parameters with and without specifications.

cues collectively have an effect to the choice of suitable beef in the retailing shop. In this study, the reviewed search beef quality cues are personal relation (between seller and customer), price, branding/packaging, freshness, marbling and beef presentation/type of cut. Other search beef quality cues in this research are beef color, fat content, butchers' location, advertisement/promotion, beef cleanliness, beef selling certification and smell (aroma).

The second hypothesis, on the other hand was testing the correlation between customers' responses on quality attribute cues that impacting their respective preference on beef and their respective choice on the photos of standard graded beef. Whereas, the last hypothesis in this study compared the results between the surveyed cities based on beef quality attribute cues, which were regarded as influencing factors on consumer preferences.

Various studies have been conducted in consumer behavior towards decision making on procuring various products at purchasing points. Most of the studies were comprehensive detail the means in which consumers make decision by involving search, experience and credence quality attributes [15]. Other studies were far beyond to extent that the consumer preferences on meat varieties including beef were match in both one-dimensional and multidimensional perspectives. Different from other studies in which beef quality cues were identified and ranked, this research compares beef quality cues with customers preferences based on their choices on the type of beef displayed photo. It is also focuses on the assessment of the consumer preferences and beef quality attributes cues by thoroughly exploration of consumer behaviors from other studies and field. In this respect, the study is significant as it elaborates the current means for determination of the suitable beef in retailing shops. In addition to that, the study has theoretically and/or empirically brought an alternative means of assessing the quality cues, i.e., by comparing consumers' choices based on their responses on 
the displayed quality cues. All of these were statistically justified by Multi-regression analysis for analyzing predictor variables (for both removing unrelated predictor variables and testing their Multicollinearity and Kruskal-Wallis one way analysis of variance (ANOVA) by rank to compare the consumers' preferences.

\section{Determination of Beef Quality}

\subsection{User Based Approach}

Although the quality of beef is differently interpreted among consumers, nutritional as objective entity and eating quality aspect of quality have been recorded as the most important dimensions in user based quality approach [9] [16]. This has been described based on the human factors that optimize selection of cuts in order to fit dietary and palatability needs of consumers. The categorization of consumer needs in beef is based on beef cleanliness, estimated yields, eating quality and cuts. Although this categorization has been used as an important selling factor in Australia, Europe, Asia and North America, it is too unclear to be applicable in beef trading across different regions [16].

\subsection{Approaches Determination of Quality in User-Based Dimension}

Quality in user-based dimension is determined by one among the four main approaches, i.e., economics of information, multi-attribute, hierarchical, and integrative [16]. In economics of information the subjective quality of a product is determined based on the economic theory on product quality during which a major distinction between search, experience and credence characteristics is made [16]. The weakness in this approach is that the characteristics are neither visible nor validated by consumers even after trying the product.

On the other hand, the multi-attribute approach of quality determination for a product is considered as a multi-dimensional evaluation, during which, its overall quality is described by a set of cues that are perceived by the consumer [17]. In this approach the interrelationship of attributes is not taken into account, i.e., all the attributes are treated at the same level. For example, consumer may either infer taste from price or healthiness from fat content [16]. In addition to that the importance of the attributes is assumed to be constant although it may be dependent on purchase situations, e.g., weighting of taste and convenience may be different for weekday and weekend use.

The next one is hierarchical approach with means-end chain model as a well-established model. This approach describes the means at which consumers infer some attributes from other attributes. The approach is elaborated by the means-end chain model that describes the links, which a consumer establishes between product perceptions and abstract purchase motives or values. For example, a consumer will inspect the color of a piece of meat (a product characteristic) because he believes it to be related to the taste of meat when prepared 
(expected quality), and the taste will lead to enjoyment while eating (abstract purchase motive). The product attribute (in and by itself) is only relevant to the extent that the consumer expects to lead to one or more desirable or undesirable consequences [17].

The last one is integrative approach that focuses on the determinants of experienced as opposed to expected quality and the technical product specifications, which will determine both the intrinsic quality cues the consumer can perceive and the quality finally experienced. The approach is silent on credence attributes like safety, environmental quality, and health although they are recognized as important in food choice motivations. This study draws data from consumers' perceived beef quality as users of the product. Such users were found at points of sale of beef (butchers).

In connection to this, other literature reported the means in which the described inaccuracy in determination of the quality of products is corrected by using the concept of usability [18] [19]. The quality of the product in user-based dimension is inaccurately measured following the inclusion of consumers' perceptions, needs and goals in its definition [20] [21] [22] [23]. This concept is embracing the user-perceived quality by connecting the quality to the needs of the user of an interactive product and the quality of use [18] [23]. Quality of use is an extent to which a product satisfies the stated and implied needs when used under the given conditions [19]. This moves the focus of quality from the product in isolation to the particular users of the product, the tasks and the context in which it is used [18]. Since the purpose of the noted product is to help the user to achieve particular goals, the measures of quality of use can be termed as quality of use measures, i.e., the effectiveness, efficiency and satisfaction based on which users can achieve specified goals in different environment [19] [22].

\subsection{Determination of Beef Quality}

The determination of beef quality in user-based dimension involves the optimum needs and motivations based on economic and deeper levels involving emotions, cultural norms and values, and group affiliations [20]. In connection to this, it was highlighted that the term optimum in beef quality should not be considered as a single unchangeable state, but it depends on the end use of the meat and even the way the meat is cooked. For, example, the popular beef based cuisine in different continents as reported in literature were observed to be similar for grilled, deep-fried and stewed beef, but differences arise among different regions on case of smoked, raw soup and burger uses as shown in Table 2. Thus, consumer preferences are also dependent on expected uses and preparation.

User-based approach is connected to the fact that, any product can be conceived as an array of its related cues during which, each cue provides a basis for various impressions [1] [4] [18]. The quality aspects that are unobservable at purchasing point are known as quality attributes and normally linked to the product attributes [1] [13]. They are sometimes known as quality criteria that are functional and psychological benefits or consequences provided by the 
Table 2. The comparison of popular beef-based cuisine in different continents (designed and customized based on the riviewed literature [21] [24].

\begin{tabular}{ccccc}
\hline \multirow{2}{*}{ Beef-based cuisine } & \multicolumn{5}{c}{ Continents } \\
\cline { 2 - 5 } & Africa & Asia & Europe & America \\
\hline Grilled & $\sqrt{ }$ & $\sqrt{ }$ & $\sqrt{ }$ & $\sqrt{ }$ \\
Deep/stir-fried & $\sqrt{ }$ & $\sqrt{ }$ & $\sqrt{ }$ & $\sqrt{ }$ \\
Stewed & $\sqrt{ }$ & $\sqrt{ }$ & $\sqrt{ }$ & $\sqrt{ }$ \\
Smoked & $\times$ & $\sqrt{ }$ & $\times$ & $\times$ \\
Steamed/braised & $\sqrt{ }$ & $\sqrt{ }$ & $\sqrt{ }$ & $\sqrt{ }$ \\
Sausage & $\sqrt{ }$ & $\sqrt{ }$ & $\sqrt{ }$ & $\sqrt{ }$ \\
Raw soup & $\times$ & $\times$ & $\sqrt{ }$ & $\sqrt{ }$ \\
Burger & $\times$ & $\times$ &
\end{tabular}

product, and they are observable prior to consumption [1]. Which product attributes are quality attributes thus depends on the priorities of the individual based on one among these and or all the following criteria, i.e., satisfaction, worries and trust... The quality attributes are described as experience quality attributes, i.e., those ascertained on the basis of actual experience on consumption of a product, e.g., in case of beef we have tastes, tenderness and leanness [13]. The quality attributes are also described as credence quality attributes, the one that cannot be ascertained even after consumption of product that are alternatively known as attributes of concern to the consumer although they are not accessible cues at purchasing point [13] leading to a loose connection between beef quality cues at the sell point and those at end-use. Despites the noted description, the situation was simplified based on the definition of quality convention in specifying rules to characterize products as per user-based approach [17]. Some of the existing forms of conventions are quality traits based on origin or animal breed, on production methods, on specific supply-chain structure [13]. For, example in a case of production methods, the practices involved during meat production are animal feeding, the use of hormones, friendly environmental as well as animal welfare [13]. The success on the noted simplification is quantified by parameters like the market size, the price differential for producers/consumers, and by raising consumer expectations based on their preferences.

Quality of use is determined by two main components, namely, product and context in which it is used, i.e., the particular users, tasks and environment [18] [23]. It is deduced from the interaction between the user and product while carrying out a task in a technical, physical, social and organizational environment as shown in Figure 2. This brings the understanding to the conviction that, the quality of any product is determined based on the measure of its quality of use in particular context under the influence of the situation in which it is used [18].

Currently, the quality of use and or usability is measured by the methods of the European Metrics for Usability Standards in Computing (MUSiC) project 


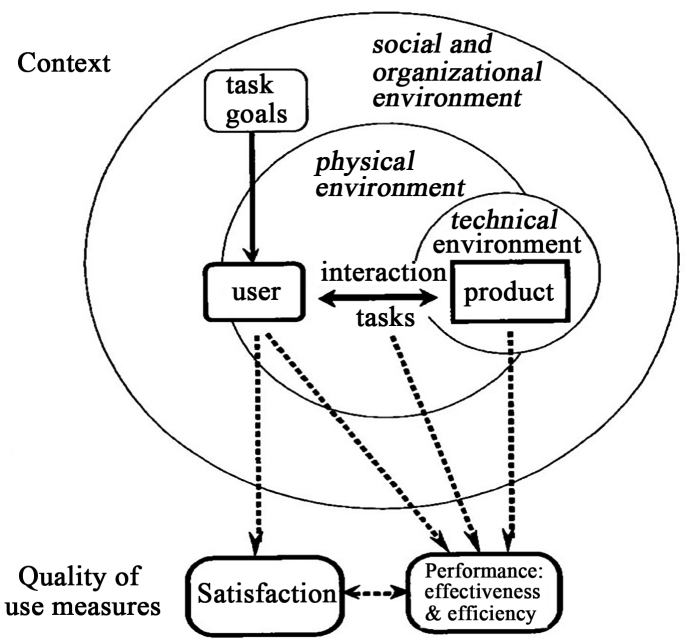

Figure 2. Beef Quality of use measured by the context of user-product interactions [18] [19].

[18]. This model fits well the beef quality determinants and consumer preferences. These methods provide valid and reliable means of specifying and measuring, while diagnosing feedback which enables the design to be modified to improve usability [18]. The MUSiC methods proved to be successful since they include tools and techniques for measuring that satisfy consumers [18] [24] as shown in Table 3.

\section{Methodology}

\subsection{Study Area}

The study was carried out in Mbeya and Dar es Salaam and conducted based on the established hypotheses along the pre-slaughtering, slaughtering and post slaughtering chain between January and April 2017. According to 2012 population and housing census, as the Dar es Salaam city with a total area of $1800 \mathrm{~km}^{2}$ has a population of 4.36 million in 2012 United Republic of Tanzania (URT), Mbeya city with $19,098 \mathrm{~km}^{2}$ has a population of 0.69 million. Dar es Salaam and Mbeya cities are characterized by high level of poverty despite the various efforts on interventions. Among other poverty indicators, the difficultness for their respective residents on accessing the basic needs in 2011 was at 5.2\% and $24.3 \%$ levels, respectively. As Dar es Salaam has six slaughter facilities with capacity to slaughter 720 cattle a day, Mbeya has three slaughtering facilities with daily capacity of 200 cattle [25]. The stock that is slaughtered in these cities is distributed to butchers that are classified based on income class of the clientele into high, middle, low and extra-low levels. During the study, data that is connected to beef quality management were collected from slaughtering facilities, carcasses distributing vehicles and beef retailing premises. In Mbeya, data was specifically collected from three slaughtering facilities, i.e., Ilemi, Uyole and Mbalizi that were purposely pointed as they being the only registered facilities around that location. 
Table 3. Chemistry of fresh beef quality (customized from lietrature [1]).

\begin{tabular}{|c|c|c|c|c|}
\hline Quality indicator & Characteristic (s) & Functional group & $\begin{array}{l}\text { Chemical compound } \\
\text { to be tested }\end{array}$ & $\begin{array}{l}\text { Laboratory } \\
\text { testing method }\end{array}$ \\
\hline \multirow{9}{*}{ Flavor } & \multirow{3}{*}{ Sweetness } & Carbohydrate (sugars) & Glucose, fructose and ribose & $\begin{array}{l}\text { Liquid Chromatograph } \\
\text { with Mass Spectrum } \\
\text { Detector (LC-MSD) }\end{array}$ \\
\hline & & Protein (Amino acids) & $\begin{array}{l}\text { glycine, alanine, lysine, cysteine, } \\
\text { methionine, glutamine, succinic }\end{array}$ & \multirow{4}{*}{$\begin{array}{l}\text { Gas Chromatograph } \\
\text { with Mass Spectrum } \\
\text { Detector (GC-MSD), }\end{array}$} \\
\hline & & Organic acids & $\begin{array}{l}\text { glycine, alanine, lysine, cysteine, } \\
\text { methionine, glutamine, succinic }\end{array}$ & \\
\hline & \multirow{2}{*}{ Sourness } & Protein (Amino acids) & $\begin{array}{l}\text { lactic, inosinic, orthophosphoric } \\
\text { \& pyrrolidone carboxylic }\end{array}$ & \\
\hline & & Organic acids & $\begin{array}{l}\text { Succinic, lactic, inosinic, ortho-phosphoric } \\
\text { and pyrroldone carboxylic }\end{array}$ & \\
\hline & \multirow[b]{2}{*}{ Bitterness } & Hypoxanthine & Hypoxanthine & \\
\hline & & Protein (Amino acids) & $\begin{array}{l}\text { Arganine, leucine, tryptophan } \\
\text { anserine and carnonsine }\end{array}$ & \\
\hline & \multirow{7}{*}{$\begin{array}{l}\text { Dark, red, } \\
\text { pink and } \\
\text { colored }\end{array}$} & Denaturing & 4-hydrox-5-methyl-3(2H)-furanone (HMF) & $\begin{array}{l}\text { Ultra violet-visible r } \\
\text { (UV-VIS) Spectrophoto- } \\
\text { mete }\end{array}$ \\
\hline & & Water holding capacity & Ultimate $\mathrm{pH}$ & $\mathrm{pH}$ meter \\
\hline \multirow{5}{*}{ Meat color } & & Protein (Amino acids) & Myglobin & \multirow{3}{*}{ GC-MSD } \\
\hline & & Lipid (Fatty acids) & Linoleic acid & \\
\hline & & Organic acids & Lactic & \\
\hline & & Anti-oxidants & Vitamin E & LC-MSD \\
\hline & & Transition Metals & Copper, iron & $\begin{array}{c}\text { Atomic absorption Spec- } \\
\text { trophotometer } \\
\text { (AAS) }\end{array}$ \\
\hline \multirow{4}{*}{ Tenderness/texture } & \multirow{4}{*}{ Toughness } & Amino acids & Amino acids & \multirow{3}{*}{ GC-MSD } \\
\hline & & Organic acids & Lactic & \\
\hline & & Fatty acids & Linoleic acids & \\
\hline & & Water holding capacity & Ultimate $\mathrm{pH}$ & $\begin{array}{l}\text { UV-VIS Spectrophoto- } \\
\text { meter }\end{array}$ \\
\hline
\end{tabular}

Dar es Salaam city was selected because of its unusually high population due to its metropolitan characteristics which attract many people looking for employment in the industries. Mbeya city was also targeted due to the availability of consumers from working that includes government departments, Institutions, private companies and entrepreneurs [26]. In addition, these cities were chosen as study areas as they have direct access to other countries through Julius Nyerere and Songwe International Airports, respectively, being potential for export of meat from Tanzania. 


\subsection{Data Collection Techniques}

Beef quality determination indicators were formulated based on the data that were collected from both secondary (assessment of literature records) including scientific reviews and research articles and primary sources of information (field data collection) as conceptualized in the data gathering model in Figure 3.

\subsection{Data Collection Techniques}

\subsubsection{The Type of Data}

In this research, secondary data were collected from literature by using systematic review approach in which a number of scientific publications were reviewed in connection to their respective relevancies focusing on the study matter. In the systematic review, literature were organized to not only the classes (scientific articles and reviews), but the number of publications that detailed quality cues that impact customers preferences on beef in a consolidated standard of reporting trials (CONSORT) flow diagram. The final results in connection to the secondary data were presented in clustered columns of quality attribute cues across the search, experience and credence attributes. Primary data, on the other hand, were collected from beef retailing shops by recording the customers' opinion on the photo of standard graded beef and a provided list of quality attribute cues that impact customers' preference on beef. This type of data was further recorded in clustered columns that were plotted as percentage

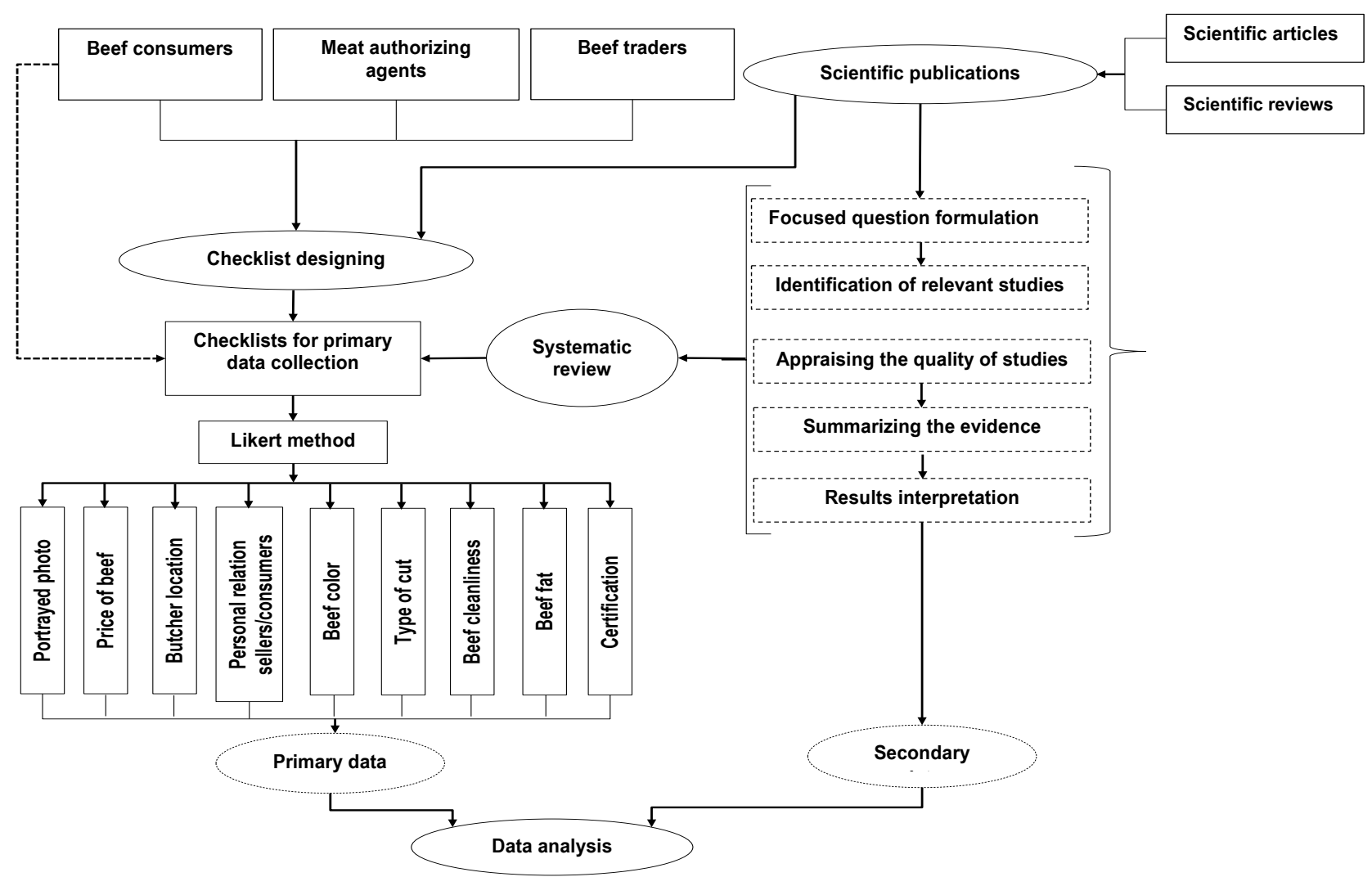

Figure 3. Conceptualized model developed for data collection on beef quality attribute cues based consumer preferences. 
of customers against their degree of acceptance on the assessed stimuli (photo of standard graded beef and a list of quality cues). The final data type resulted from statistical analysis which was presented in figures and tables before drawing the final conclusion.

\subsubsection{Primary Data Collection Checklists}

This study on beef quality preferences were conducted by interviewing the purposively identified customers at different beef retailing shops that were conveniently selected from a list of pre-inspected food processing units. In this respect data connected with thirteen (13) beef quality cues in search quality attribute as reported in literature [1] [10] [17] [22] were collected by using a structured checklist between January and April 2017 through interviewing beef customers (208 in Dar es Salaam and 98 in Mbeya). This sampling period was chosen because it includes the maximum (January) and minimum (April) lean periods as per trigonometric crop price seasonality estimation as indicated in other literature [27]. This was involved the collection of consumers' opinion on their choice to both quality attribute cues and the suitability of beef in the portrayed photo. The gathered data were then entered in the established database before being analyzed in the spread sheet of Microsoft excel version 2010 software with respect to the objective and statistical hypotheses established.

In this study, checklists were designed for recording the ranked responses from beef consumers in the pre-listed statement based on the Likert scale technique. It is empirical study that was designed based on the gaps identified by the past work against the similar problem, and have not yet been examined [1] [13]. The designing was carried out to purposively identify beef trading stakeholders buying beef in the surveyed butcher shops that were conveniently selected from the list of pre-inspected butchers that is obtained at Tanzania Food and Drugs Authority (TFDA) Database. While the surveyed wards in these research were randomly chosen, the cities were purposively selected based on the reflection of the potential market of beef in connection to both general population and their respective exporting international airports.

The compiled responses of consumers based on Likert items with respect to the portrayed photo and search beef quality cues were analyzed after checking their reliabilities by Multi-linear regression analysis in the Spread sheet of Microsoft Excel version 2010 to both identify predictor variables (search beef quality cues) and their multicollineality effect During this study, multi-linear regression model was also used in comparing the customers' decision on the portrayed photo based on their responses on the search beef quality cues between the surveyed cities. In this regards, the null hypothesis, that states that all beef quality cues collectively have no effect on the decision made during beef quality determination in retailing shops, i.e., the coefficient of beef quality cues, denoted as $\beta_{p}$ as in Equation (1) are the same.

$$
H_{o}: \beta_{1}=\beta_{2}=\beta_{2}=\cdots=B_{p}
$$


Rejection of this hypothesis leads the testing as to whether the individual regression coefficients are significant while controlling other variables in regression model.

In addition to that, Kruskal-Wallis one way ANOVA by ranks test statistic was used to test whether the consumer preferences in the surveyed cities are statistically comparable as the data involved are non-parametric. The testing was involved the checking on the possibility of having statistical difference on rating the named indicators by consumers grouped based on the streets of the surveyed cities at $0.05 \%$ significance level (95\% confidence interval) [28]. The testing was based on ranks of the scored values and means of those ranks in a chi-squared distribution plot designed based on degrees of freedom $(k-1)$, i.e., the number of indicators being compared minus 1 and with $X$ and $Y$-axes labeled as $X^{2}$ and probability density function (PDF), respectively.

\subsection{Collection and Analysis of Secondary Data}

In this part of the study, beef quality attribute cues were identified, listed and analyzed in connection to consumers' preference from literature. Consumer preferences on beef varieties have been detailed by many studies in terms of scientific reviews and articles around the world. In this study, systematic review was used to both identify these studies and organize the outcomes in a comprehensive interpretation on the beef quality attributes cues those impacting consumers' preferences. Systematic review that describes it as the transparent and systematic process rather than specific method for data aggregation and interpretation was carried out following five main steps [14] [28] [29], i.e., framing the question, identifying relevant studies, appraising the quality of the studies, summarizing the evidence and interpreting the results.

In the first step, the focus question was stated as a query in free form before explicit structured by relating its components and designed. As it was mentioned in literature [14] [28], the framed question was used as framework for inclusion and exclusion criteria, the search and selection of relevant studies, as well as in synthesize of studies and presentation of the findings. The question was designed based on a population of interest, an intervention/phenomenon of interest, comparators, and outcomes/context of interest acronymic as PICO.

Relevant studies were identified in the second step, an activity that between January and April 2017 from ScienceDirect ${ }^{1}$, HINARI $^{2}$ and AGORA $^{3}$ websites that provide subscription-based to a large database of scientific and medical research licensed at TFDA Offices during which more than 13 million documents and 30,000 e-books were accessible. This was comprehensively and unbiased conducted by using key word identification, search strategies for multiple databases, and hand search journals as shown in other studies [14] [29]. In connec-

${ }^{1}$ ScienceDirect (https://www.sciencedirect.com/).

${ }^{2}$ HINARI Access to Research in Health Programme (http://www.who.int/hinari/en).

${ }^{3}$ Access to Global Online Research on Agriculture (http://www.fao.org/agora/en). 
tion to this, a list of records from all databases was exported directly to EndNote ${ }^{4}$ for removing duplicates. Then, the remained records were screened by reviewing the title, abstract or both, in order to remove, off topic records, citations in non-understandable languages and further duplicates. The remained list of records was further screened by focusing on the citations that were published in journal articles that were peer-assessed, thus, acting as a quality assurance criterion of the data and results presented. As it was mentioned in other literature [14], papers that were not in the Journal of Citations Report (JCR), that have $\mathrm{H}$ index ${ }^{5}$ less than 20 were not included in this analysis.

In the next step, the records were classified into reviews and research articles, the classes that were applicable for identification and relative ranking of beef quality attribute cues, respectively. The identified reviews were assessed by reading title and abstract before classifying them based on either only one beef quality attribute cue in detail was considered or several attribute cues simultaneously. The full texts of the identified and separated reviews were analyzed for their relevance and quality. Quality was analyzed based on the key sources, clarity and comprehensive description of the argument and novelty in the reviews. Similarly, the list of the selected research articles was obtained by using the same process as in the selection of appropriate citations for the reviews.

Research articles that describe relative importance of different quality indicators from consumer perspective were then identified. The identified articles were further refined based on the described ranking procedures to remain with papers that are clear enough to quantify relative ranking of indicators. Beef quality determination indicators explored from the refined papers were next classified based on search, experience and credence quality and their individual importance within each study was re-scaled as per steps indicated in Table 4.

Table 4. Steps for rescaling individual quality attribute cues within each of the surveyed study (designed and customized from [14] [28].

\begin{tabular}{|c|c|}
\hline Step & Activity \\
\hline Ranking indicators within articles & $\begin{array}{l}\text { The observed indicators were ranked starting with } 1 \text {, for the } \\
\text { least important one to the given maximum level in the article. }\end{array}$ \\
\hline Re-scaling the previous ranking & $\begin{array}{l}\text { The ranked indicators were re-scaled from } 1 \text {, for the least } \\
\text { important indicator within the article to } 3 \text { for more } \\
\text { important indicator within the article based on Equation (1). }\end{array}$ \\
\hline $\begin{array}{l}\text { Strengthening indicators by using } \\
\text { arbitrary factor based on the } \\
\text { number of indicators } \\
\text { considered within the paper. }\end{array}$ & $\begin{array}{l}\text { A factor of } 1 \text { was given for the minimum } 2 \text { indicators and } \\
3 \text { to the maximum number of } 16 \text { indicators that was } \\
\text { presented across all papers based on Equation (2). }\end{array}$ \\
\hline Scoring within a paper & Equation (3) \\
\hline Scoring for individual indicators & $\begin{array}{c}\text { The final score }\left(f_{s}\right) \text { for individual indicators } \\
\text { was obtained as a sum across all papers }\end{array}$ \\
\hline
\end{tabular}

${ }^{4}$ Is an industry standard tool for publishing and managing bibliographies, citations and references on the windows and Macintosh.

${ }^{5}$ Is calculated by counting the number of publications for which an author has been cited by other authors at least that same number of times (this means that the scientist has published at least 20 papers that have each been cited at least 20 times). 
The previous ranking, $R_{R}$, was re-scaled from 1 (as the least important indicator within the article) to 3 (more important indicator within the article) based on Equation (1).

$$
R_{R}=1+\left[\frac{(3-1)}{\left(m_{l}-1\right)}\right] \times\left(g_{l}-1\right)
$$

Equation (1). Rescalling the previous ranking

In this regards, $m_{b}$ indicates maximum level of indicators, $g_{b}$ shows a given level of indicator (The number of levels in this equation is not necessarily the same as the number of indicators if some indicators had the same score.

$$
n_{i f}=1+\left[\frac{(3-1)}{\left(m_{i}-2\right)}\right] \times\left(n_{i}-2\right)
$$

Equation (2). Determination of number of indicators factor $n_{i f}$ where, $m_{p}$ maximum number of indicators in the reviewed paper, $n_{p}$ number of indicators given in the reviewed paper.

$$
f_{s}=1+\left(R_{R} \times n_{i f}\right)
$$

Equation (3). Final score, $f_{s}$ of each quality cue within a reviewed scientific publication.

In the final step, data were synthesized in a tabular summary of the all the surveyed studies related to each of the key quality attribute cues across search, experience and credence identified as important and facilitate analysis of comparison across studies form like other descriptive synthesis. In this respect the gathered data were entered in designed database in Microsoft excel version 2010 software before being analyzed and interpreted. Data were further presented in a tabular summary indicating beef quality attribute cues, connected with scientific publication reviewed and their respective ranking in figures as clustered columns. Since this is observational study, data were written up in CONSORT) flow diagram as indicated in other studies [29].

\section{Results and Discussion}

\subsection{Beef Quality Attribute Cues and Consumer Preferences}

Beef quality attribute cues that impacting consumer preference explored from secondary sources of information were presented across the five main steps of systematic review. First, it includes the focus question, which is asked that 'is the customers' choice on a photo of standard graded beef similar to their responses on quality attribute cues that impacting their preferences'.

In line with this question, the structured components are: customers that responded on both photo of beef and quality attribute cues were noted as the population of interest; photo of USDA standard graded beef, was expressed as an intervention of interest; beef quality attribute cues, were explained as the comparator of interest; and customer preferences were outcome of interest. Then, results with respect to second to the final steps of the systematic review processes were presented in CONSORT diagram as shown in Figure 4. 


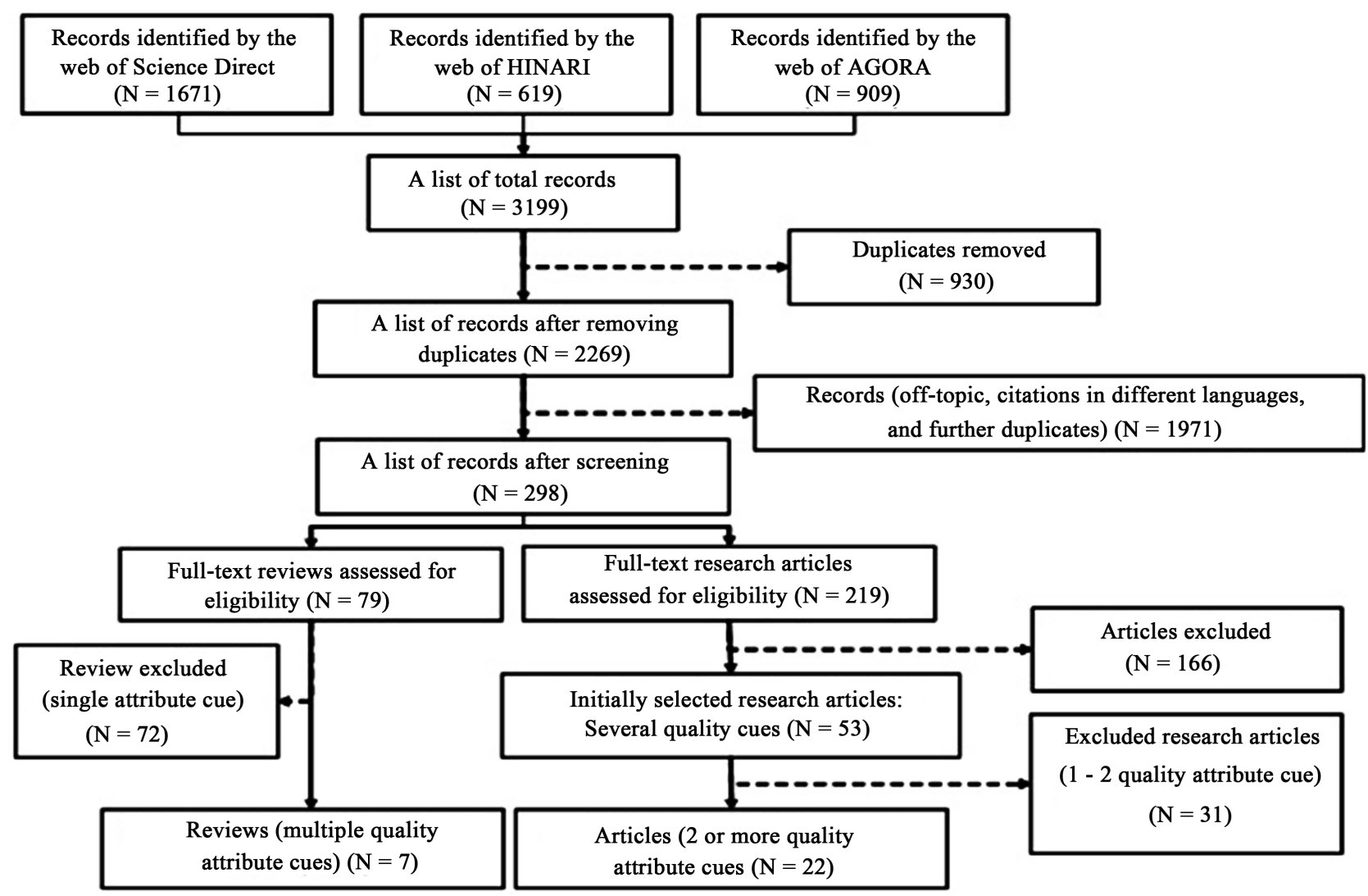

Figure 4. Search results for beef quality attribute cues in a systematic literature review process (adapted and customized from other studies [14] [28] [29]).

In the flow a list of 930 duplicates was excluded from 3199 records that were obtained from ScienceDirect, HINARI and AGORA by using EndNote. The systematic review was further, elaborated the means in which, a list of 1971 citations among of 2269 records was identified as irrelevant, hence excluded and remaining with a total of 298 documents. The remained records were further classified into 79 reviews and 219 research articles. The assessment and classification of reviews as per either only one indicator in detail or several indicators simultaneously involved resulted to a total of 5 reviews. Similarly a total of 18 articles addressing several indicators were selected for ranking and excluding 32 that dealt with $1-2$ indicators. Fifty three articles that contained information on relative importance of different beef quality determination indicators as per consumers' perspective were initially identified. Among the identified papers, 32 were excluded in ranking due to the ambiguous on ranking of the identified indicators. The remaining 28 publication papers resulted to a total of 25 quality attribute cues that impacting customers' preferences whose individual importance within each study was rescaled as shown in Table 5 . The systematic review was finally resulted to 7 reviews and 22 articles as the appropriate records for identification and ranking of beef quality cues.

The identified quality attribute cues that affecting customers' preferences on beef were ranked based on their relative positions and percentage of scientific 
Table 5. Reviews explored for identification of beef quality attribute cues.

\begin{tabular}{|c|c|c|c|}
\hline Quality attribute & Indicators & Scientific Review (s) & Research Article (s) \\
\hline \multirow{15}{*}{ Search } & $\begin{array}{l}\text { Personal relation } \\
\text { (seller and customer) }\end{array}$ & [10] [30] & [5] [13] \\
\hline & Price & $\begin{array}{l}{[10][17][23][31]} \\
{[32][33][34][35]}\end{array}$ & $\begin{array}{c}{[3][5][6][7]} \\
{[9][13][26]}\end{array}$ \\
\hline & Branding/packaging & [10] [17] [30] [31] [33] & $\begin{array}{c}{[3][5][6]} \\
{[7][13][22]}\end{array}$ \\
\hline & Freshness & [1] [17] & $\begin{array}{c}{[3][5][6][7]} \\
{[9][13][26]}\end{array}$ \\
\hline & Marbling & [17] [34] [35] & $\begin{array}{l}{[3][5][6][7]} \\
{[13][14][26]}\end{array}$ \\
\hline & $\begin{array}{l}\text { Beef presentation/type } \\
\text { of cut }\end{array}$ & [1] [17] & [3] [7] [9] [36] [37] \\
\hline & Beef color & $\begin{array}{l}{[10][17][21][30]} \\
{[31][32][33][34]}\end{array}$ & $\begin{array}{l}{[3][5][6][7]} \\
{[11][13][14]}\end{array}$ \\
\hline & Fat content & $\begin{array}{l}{[10][17][21][30]} \\
{[32][33][34][35]}\end{array}$ & $\begin{array}{l}{[3][5][6][7]} \\
{[13][14][26]}\end{array}$ \\
\hline & Butcher's location & {$[1]$} & $\begin{array}{c}{[3][5][6][7]} \\
{[36][37][38][39]}\end{array}$ \\
\hline & $\begin{array}{l}\text { Advertisement/ } \\
\text { promotion }\end{array}$ & {$[1]$} & {$[5][6][13]$} \\
\hline & Beef cleanliness & {$[1]$} & [3] [6] [9] [13] [26] \\
\hline & $\begin{array}{l}\text { Beef selling } \\
\text { certification }\end{array}$ & {$[1]$} & [3] [36] [37] [38] [39] \\
\hline & Smell (aroma) & [10] [30] [32] [33] [35] & [3] [6] [7] [40] \\
\hline & Taste & [10] [21] [31] [32] [33] [35] & $\begin{array}{l}{[3][5][6][7]} \\
{[13][26][40]}\end{array}$ \\
\hline & Tenderness & [10] [22] [30] [32] [33] [35] & $\begin{array}{c}{[3][5][6][7]} \\
{[9][13][40]}\end{array}$ \\
\hline \multirow[t]{6}{*}{ Experience } & Juiciness & {$[10][22][30][32][33][35]$} & $\begin{array}{c}{[3][5][6][7]} \\
{[9][13][40]}\end{array}$ \\
\hline & Flavor & {$[10][22][30][32][33]$ [35] } & [3] [5] [7] [9] [13] [40] \\
\hline & $\begin{array}{l}\text { Convenient } \\
\text { (availability) }\end{array}$ & [1] & $\begin{array}{c}{[3][5][13][23]} \\
{[36][37][38][39]}\end{array}$ \\
\hline & Pathogen & [32] & $\begin{array}{c}{[6][9][24][36]} \\
{[37][38][39]}\end{array}$ \\
\hline & Nutritious & {$[31][31]$} & [3] [5] [6] [13] [40] \\
\hline & Chemical residues & [31] [31] & [3] [6] [37] [38] \\
\hline \multirow[t]{4}{*}{ Credence } & $\begin{array}{c}\text { Breed's } \\
\text { information/races }\end{array}$ & [12] [17] [34] & {$[3][5][6][7][9][13]$} \\
\hline & Animal age & [12] [22] [31] [32] [33] & [3] [9] \\
\hline & Traditional image & {$[31][34]$} & [36] [37] \\
\hline & Sex & {$[12][31][32]$} & [13] \\
\hline
\end{tabular}


publication referred. In connection to this, Figure 5 presents percentage of scientific publications referred for each of the beef quality attribute cues. The top most referred quality attribute cues were seller's information (96\%), taste (91\%) together with tenderness and juiciness that each ne has $83 \%$. The least referred quality attribute cues in the surveyed scientific publication on the other hand were advertisement and smell that each of them has $13 \%$ together with traditional image at $9 \%$

The final score for individual beef quality attribute cues were presented in terms of both overall ranking and relative ranking in ascending order across all quality attributes search, experience and credence as shown in Figure 6. The former case was described by the summed of final scores for beef color that was referred in $57.1 \%$ of the reviewed scientific publications. This analysis was overall ranked in $5^{\text {th }}$ position. Similarly the overall three top most ranked beef quality cues were tenderness, price and breed's information that were analyzed from $46.4 \%, 57.1 \%$ and $32.1 \%$ of the respective scientific publication. On the other hand, the lowest three ranked parameters were marbling, branding/packaging and pathogens which were analyzed from $35.7 \%, 39.3 \%$ and $28.6 \%$, respectively. The letter case was described based on price, tenderness and breed's information which were the top most relatively ranked summed final scores beef quality attribute cues across search, credence and experience quality attributes that were reviewed in $57.1 \%, 46.4 \%$ and $32.1 \%$

Analytical results in this study is similar to other literature [14] in which the topmost relatively ranked beef quality cues were in the highest ranks within the respective beef quality attributes.

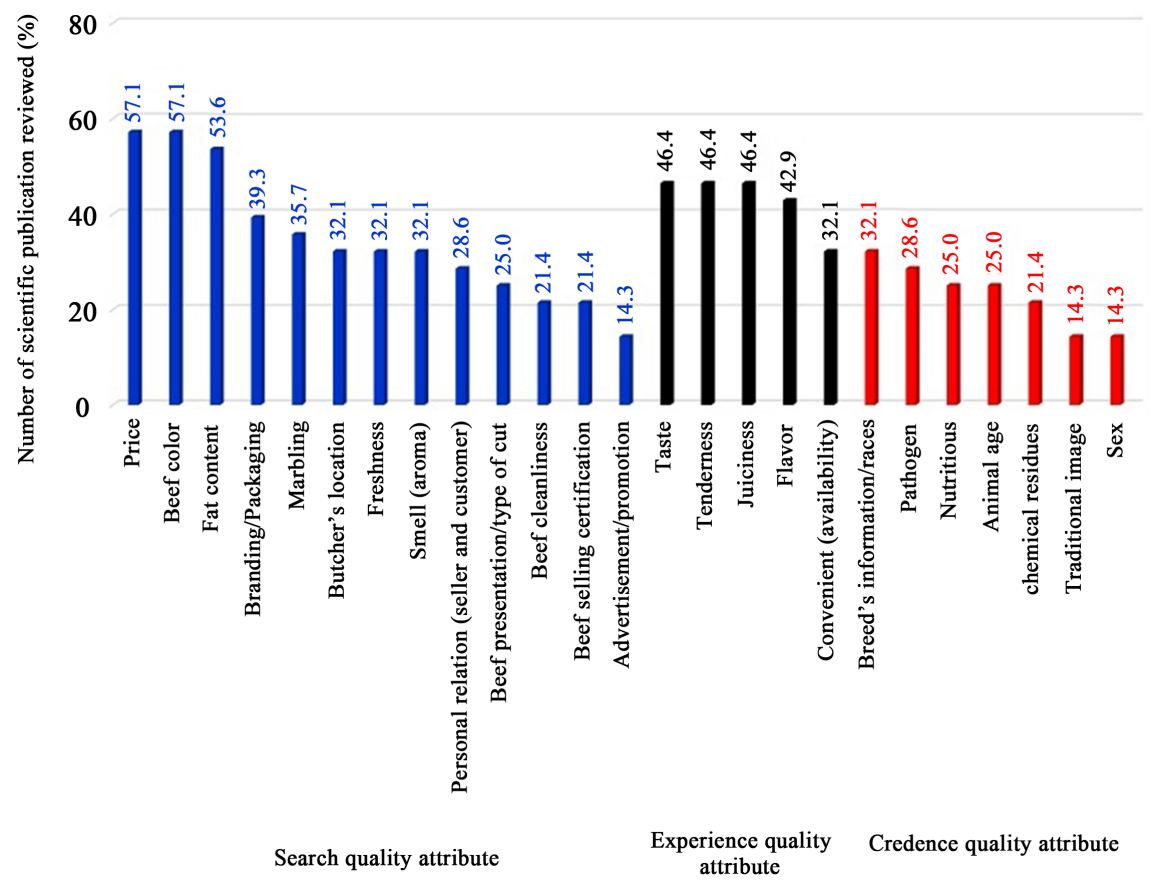

Figure 5. Beef quality attribute cues in percentage arranged according to ranking presented by the scientific publications reviewed (based on systematic review approach). 


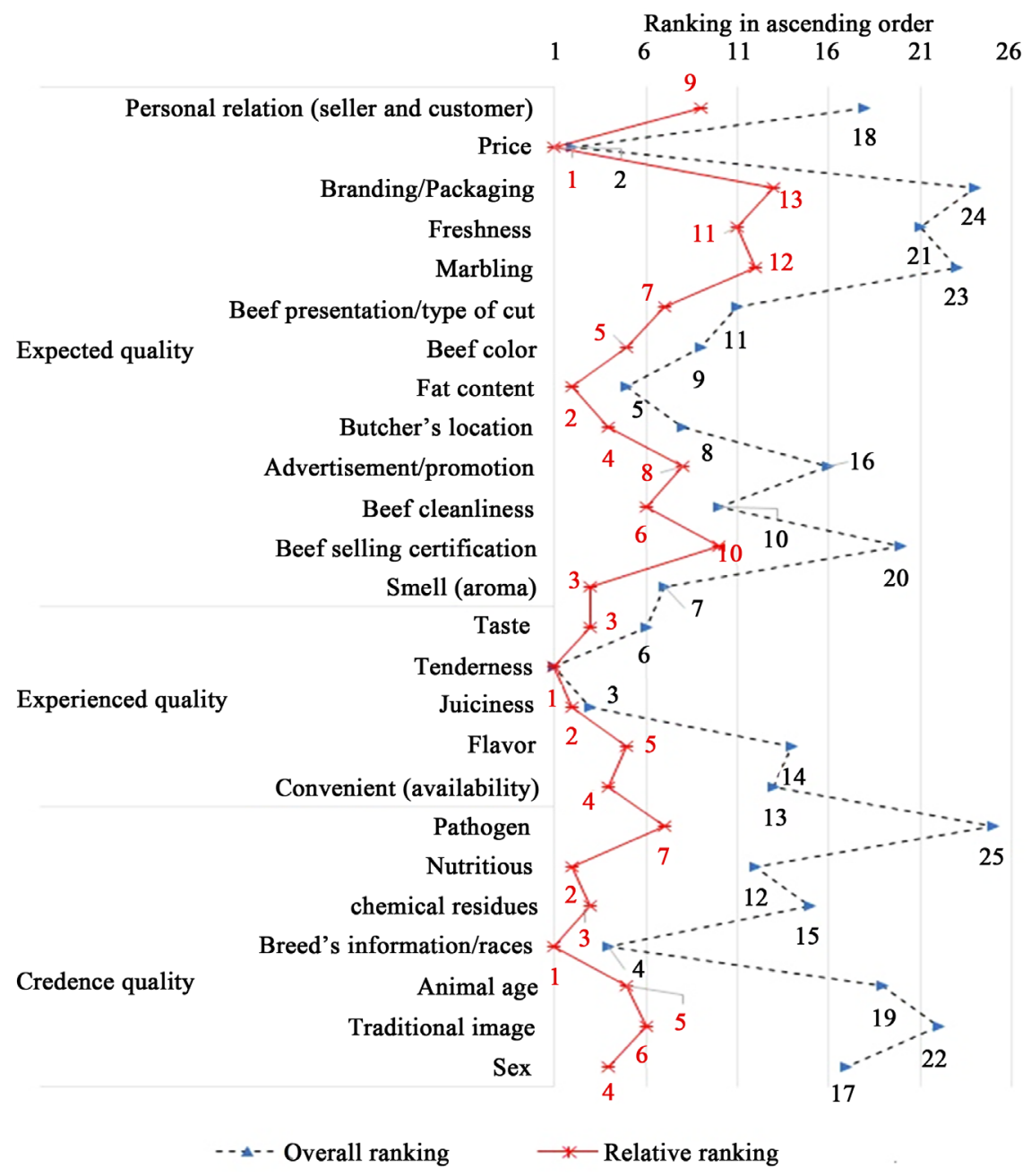

Figure 6. Relative and overall ranking of the summed final scores $\left(f_{s}\right)$ of individual beef quality attribute cues from all reviewed scientific publications arranged in ascending order across search, experience and credence quality attributes.

\subsection{Factors Affecting Consumer Preferences at the Sell Point}

\subsubsection{Consumers' Decision Based on Portrayed Photo of Beef}

This is a measure of how important each characteristic is to the respondent's overall preferences [7]. Consumers' decision on the suitability of beef is described based on the evaluation of their choices among prime, choice and select cuts of beef in photo portrayed to customers in the visited meat retailing shops USDA [41]. This a quality determination as per USDA grading model during which the best piece of beef is pointed based on the consumers' opinion. It is arranged in clustered columns as percentage of consumers' decision against the categorized type of beef portrayed as indicated in Figure 7. Prime as per USDA grading system is the highest in quality and intramuscular fat, that produced from young well fed which composes $2.9 \%$ of the carcass of the appropriately fed cattle. It was the least pointed as the best in terms of the suitability among the three displayed pieces at $25.5 \%$ and $28.6 \%$ to consumers found in visited meat retailing premises in Dar es Salaam and Mbeya, respectively. Choice, on the other 


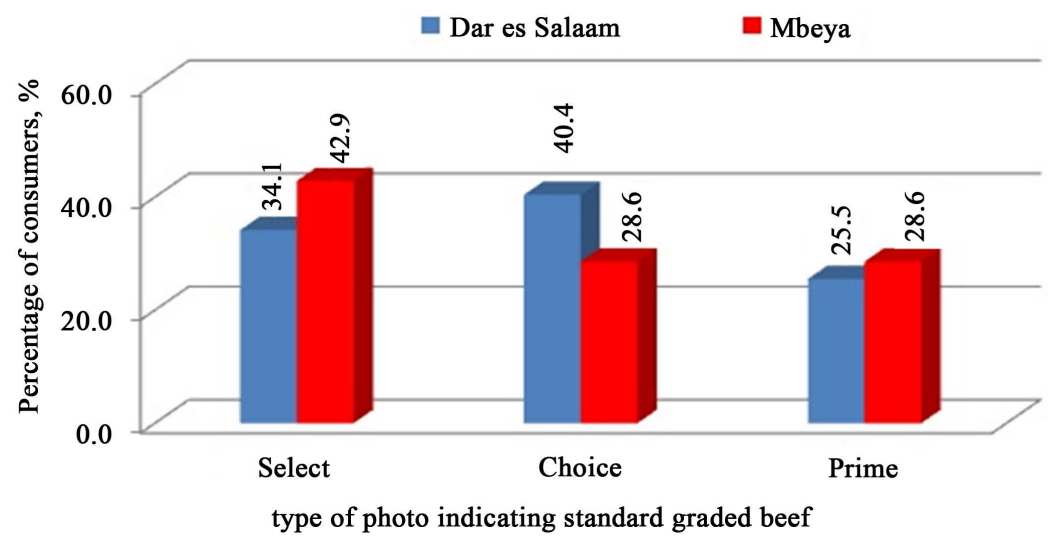

Figure 7. Number of consumers in percentage arranged according to their respective choices of the displayed photo of beef ( $N=208$ for Dar es Salaam and $N=98$ for Mbeya).

is high quality with less marbling than prime and it is widely available meat in carcasses enough to contribute $53.7 \%$ of the fed cattle total. In addition to this select beef was noted as uniform quality and normally leaner than prime and choice. It was indicated that there is dissimilarity of preferences as select and choice were separately identified as the best among the displayed pieces of beef by $42.9 \%$ and $40.4 \%$ of the visited consumers in Mbeya and Dar es Salaam, respectively. Choice and prime in the portrayed photo were similarly pointed each one by $28.6 \%$ of the consumers in the visited meat retailing shops at Mbeya.

The responses on the displayed pieces of beef in the visited cities were also reported in other literature [41]. In this regards, not only lacking of understanding of beef grading were indicated, but the influencing factors were indicated. Apart from type of cut, fat, marbling and color, beef quality determination was reported to involve the influence of other factors like price, butcher location and certification. In general beef quality determination in meat retailing shops involves both perceived intrinsic and extrinsic quality cues. It is too complicated multidimensional construct to be modeled

\subsubsection{Influence of Prices on Consumer Preferences}

Price is presented as one of the extrinsic quality attribute cues that affect consumers' preference on beef during purchasing in the retailing shops. Results in connection to this parameter were presented while assuming that the price of beef as the main factor that influencing customers at purchasing decision. It is a distribution of consumer responses on the price of beef as quality cue impacting their preferences in levels of acceptance as shown in Figure 8. The strength of price is observed to be about $36.6 \%$ and $28.5 \%$ of visited consumers in Dar es Salaam and Mbeya, respectively, did not positively accept it as reliable extrinsic cue. This quality determination indicator is absolutely not accepted by $27.9 \%$ and $12.2 \%$ of customers in Dar es Salaam and Mbeya, respectively. On the other hand, more than $65.3 \%$ of the consumers in the visited butchers in both cities accepted price as reliable beef quality determination indicator with Mbeya having $13.3 \%$ of the consumers who accepted it as the highest determinant. 


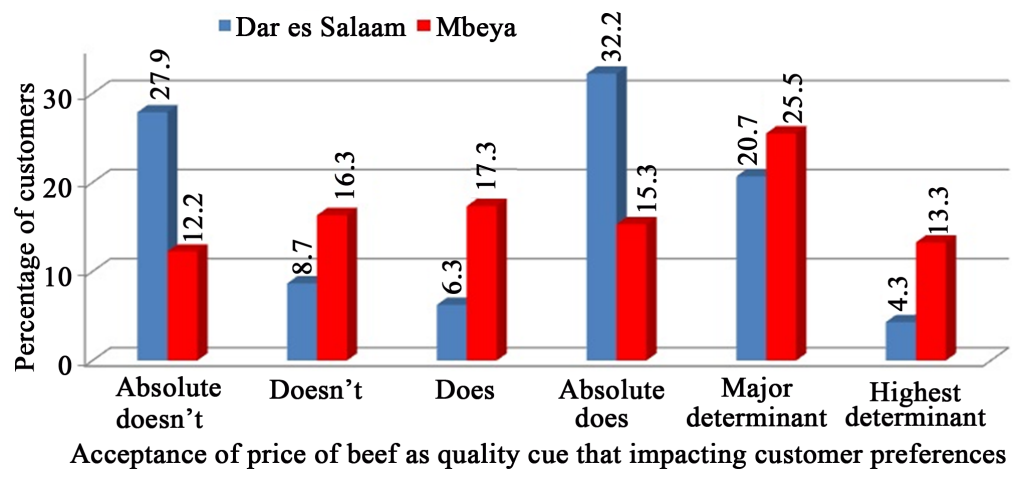

Figure 8. Distribution of consumer preferences on the price of beef as quality attribute cue impacting their preferences $(N=208$ for Dar es Salaam and $N=98$ for Mbeya).

Similar result were reported in other literature [1] [41], during which price was noted to be one of the main indicators for beef quality determination in the meat retailing shop. Additionally, the study is supported by the argument that indicate price as one of the main criteria that is often used as an indicator under assumption that the higher quality means higher price, and the vice versa is true. It is also indicated that, price is used as one of the attributes in beef purchasing by consumers during the study of assessing the beef consumer preferences in Ethiopia. As it has been indicated, the suitability of beef in meat retailing shops involves the application of price as its determinant. This study support this argument as high percentage of consumers in both cities were positively responded on the applicability of price as beef quality determination indicator. As it has been indicated, beef quality determination in meat retailing shops involves both perceived intrinsic and extrinsic quality cues. It is a complicated multidimensional construct that should be elaborated by using elaborative model.

\subsubsection{The Influence of Butcher's Location on Consumer Preferences}

The location in which beef retailing shop is found is indicated as one of the indicators for beef quality determination in this study. Evaluation results with respect to this parameter were presented under assumption that it was the main factor to be referred during purchasing decision. It is arranged according to the responses of customers on the location of butcher as the main beef quality cue affecting their preferences in degree of acceptance as shown in Figure 9.

Location as an indicator for beef quality determination is presented during which, about $72.7 \%$ and $73.5 \%$ of visited consumers in Dar es Salaam and Mbeya, respectively, were positively accept it as reliable extrinsic cue. This parameter is absolutely not accepted by $27.5 \%$ and $26.5 \%$ of customers as quality determination indicator in Dar es Salaam and Mbeya, respectively. It is also noted that $6.3 \%$ of the consumers in Dar es Salaam were absolutely rejected location as an appropriate indicator for beef quality determination. The same composition of consumers in Dar es Salaam was accepted location as the highest for beef quality in meat retailing shops. On the other hand, this parameter was both absolutely rejected and very positively accepted in Mbeya as appropriate 


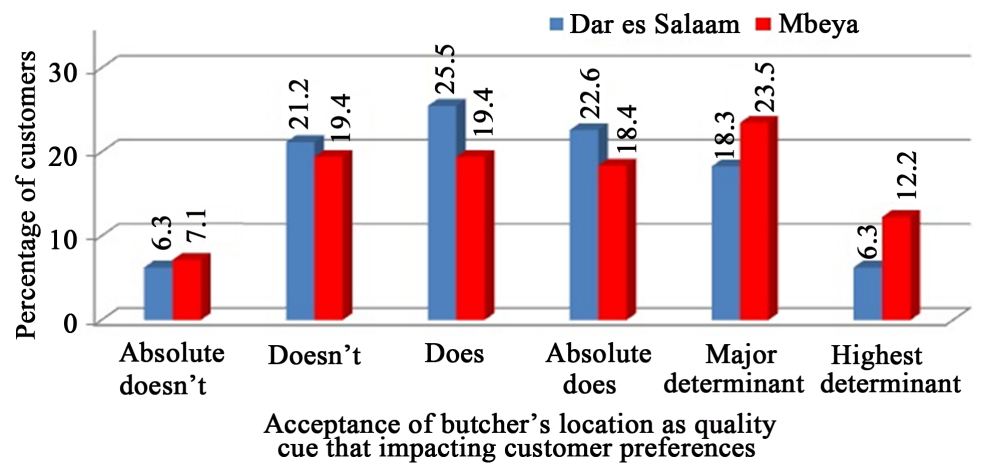

Figure 9. Distribution of consumer responses on butcher's location as beef quality attribute cue that influence their preferences on beef $(N=208$ for Dar es Salaam and $N=$ 98 for Mbeya).

beef determinant indicator by $7.1 \%$ and $12.2 \%$ of the visited consumers, respectively. This study supports [42] that indicate the influence of location of meat retailing shops as one of the appropriate indicators for consumers on determination of the suitable beef. Additionally, another literature [43] highlights location as one of the main factors that is highly considered in the selection of eight stores at a local shopping center. Determinant of location to beef suitability is justified by the fact that the choice of retail is made due to some social motivation, such as the honor acquired through the consumption of specific type of product or the frequenting of certain places... Similarly, other literature indicated the means in which price as a purchasing tool, influences purchasing decision in particular retail outlets [42] [43]. Generally, retail outlets which offer good quality products at a lower price will attract more consumers. As it has been indicated, consumers' decision on beef retailing shop includes location as one of main judging criteria for its selection. It is positively accepted by most of the beef consumers. Location is further described as the concept of convenience as respondents indicated that their preferred retail outlet was close to where they either lived or worked.

\subsection{The Influence of Personal Relation between Sellers and Consumers}

Personal relation between sellers and consumers in beef retailing was noted as one of the consumer influencing factor on their respective preferences on beef. The assessment of this parameter was presented as the major factor that influencing consumer preference on beef. It is a customer's responses on their respective personal relation with sellers as the top most influencing factor distributed in the degree of agreement as shown in Figure 10.

The strength of relation is observed to be about $69.7 \%$ and $69.3 \%$ of visited consumers in Dar es Salaam and Mbeya, respectively, which positively accept it as reliable beef quality determinant. This quality determination indicator is absolutely not accepted by $30.3 \%$ and $30.7 \%$ of customers in Dar es Salaam and Mbeya, respectively. On the other hand, approximated discrepancy of $10 \%$ of the 


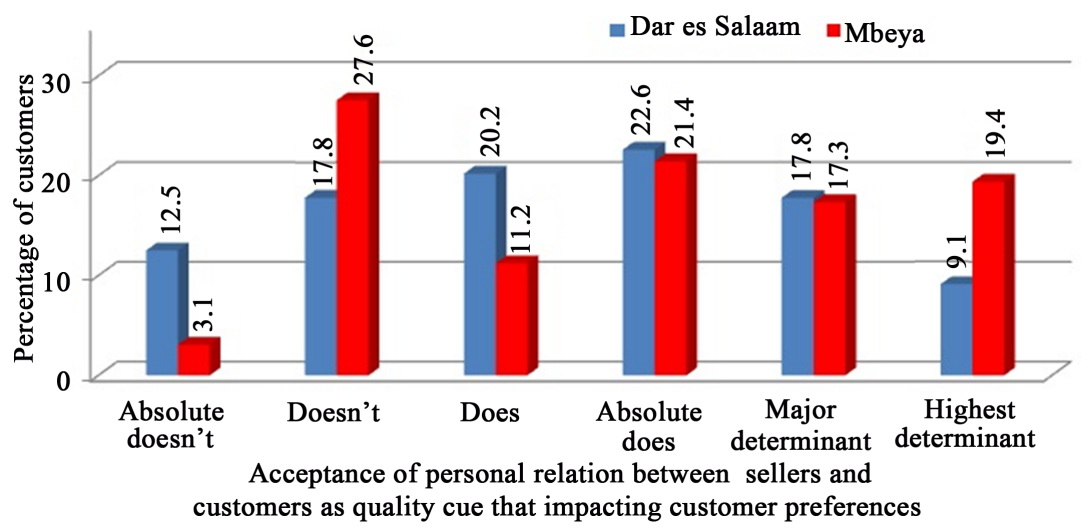

Figure 10. Distribution of consumer responses on personal relation with sellers as the beef quality attribute cue affecting affecting their preferences on beef $(N=208$ for Dar es Salaam and $N=98$ for Mbeya).

consumers is observed in terms of both absolutely rejection and acceptance relation as the highest determinant. The findings of this research are similar to earlier studies that consider personal relationship as one of the beef quality determination indicator in which consumers place much value on being served by butchers of the same ethnic race and religion in traditional market [43]. It was indicated that good relationship between vendors and customers in the traditional market (23\%) was important motive compared to those shoppers who purchase meat in modern retail outlet (3\%) [43]. It was also reported in other literature that the Arab Islaelis prefer to buy fresh meat from a known and trusted source [43] [44]. Additionally, relation is further described as the concept of convenience as respondents indicated that their preferred retail outlet was close to where they either lived or worked.

\subsection{The Influence of Appearance of Beef on Consumers Preferences}

\subsubsection{The Influence of Beef Color}

Beef color is presented as one among the quality attribute cues that influencing customers' decision at purchasing outlets. The evaluation results in connection to this parameter was indicated as the highest criteria that affecting the customers' preferences on meat in the retailing outlet. The assessment of this parameter was presented as the major factor that influencing consumer preference on beef. It is a customer's responses on beef color as the most important influencing factor arranged in the degree of acceptance with respect to Likert item as shown in Figure 11.

The observation of beef color in quality determination is presented during which, about $70 \%$ of visited consumers in each of the visited cities, were positively accept it as reliable intrinsic cue. This parameter is absolutely not accepted by $30 \%$ of customers as quality determination indicator in both cities. It is also noted that $7.7 \%$ of the consumers in Dar es Salaam were absolutely rejected location as an appropriate indicator for beef quality determination. The same 


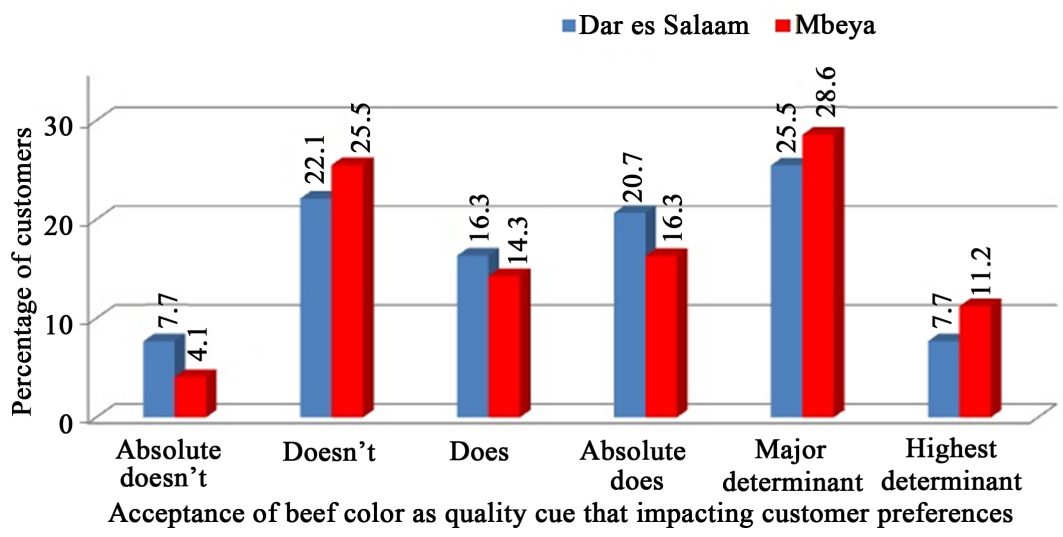

Figure 11. Likert scale of consumer responses on beef color as a quality attribute cue affecting their beef preferences ( $N=208$ for Dar es Salaam and $N=98$ for Mbeya).

composition of consumers in Dar es Salaam was accepted location as the highest for beef quality in meat retailing shops. On the other hand, this parameter was both absolutely rejected and very positively accepted in Mbeya as appropriate beef determinant indicator by $4.1 \%$ and $11.2 \%$ of the visited consumers, respectively. Color as beef quality determination indicator is identified as one of the main intrinsic cues in which consumers based on pointing suitable beef in meat retailing shop [1] [45]. As it has been indicated, consumers' decision on beef retailing shop includes color as the quality determinant. Additionally, color is further described as the parameter that indicated that their preference on type of beef in retail outlet.

\subsubsection{The Influence of Type of Cut}

Type of cut of beef is presented as a beef quality cue that influences customers' preferences on beef in the selling outlets. In this study, type of cut was expressed while assuming that it was the only criteria to be referred at purchasing point. It is a customer's responses distributed across the degree of acceptance that is appropriate factor that influencing their respective decision as shown in Figure 12.

Type of cut is presented as an indicator for determining beef suitability during which, about $68.4 \%$ and $85.7 \%$ of visited consumers in Dar es Salaam and Mbeya, respectively were positively accept it as reliable intrinsic cue. This indicator is absolutely not accepted by $31.7 \%$ and $14.3 \%$ of the visited customers in Dar es Salaam and Mbeya, respectively. The general responses of the consumers on type of cut in beef are not uniform due to the noticeable variation of consumers between the visited cities. This study is in line with other literature [46], in the evaluation based on a copy of the tender select concept card revealed $89 \%$ of consumers were definitely or probably prefer it if it could be available in the visited store. Additionally, other literature [47] supports this study as it noted that consumers were willing to pay more for tender meat. As it has been indicated, consumers' decision on beef retailing shop includes type of cut as the quality determinant. Additionally, type of cut is further described as the parameter that indicated that their preference on type of beef in retail outlet. 


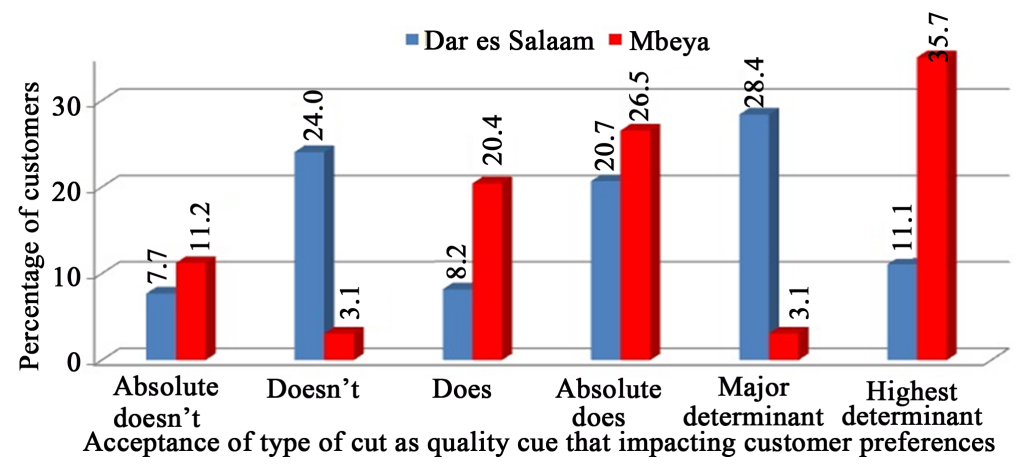

Figure 12. Distribution of consumer responses on type of cut as beef attribute cue affecting/influencing their respective beef preferences $(N=208$ for Dar es Salaam and $N=98$ for Mbeya).

\subsubsection{The Influence of Beef Cleanliness}

Beef cleanliness (without blood) is presented as one of main factors that that influencing customers' preferences on beef in the selling outlets. In this study, beef cleanliness was presented as main quality determinant under ignorance of other quality attribute cues. This is a customer's responses distributed across the levels of acceptance that beef cleanliness is the main factor that influencing their respective decision as shown in Figure 13.

Indication of beef suitability is presented as per beef appearances during which, about $70.2 \%$ and $81.6 \%$ of visited consumers in Dar es Salaam and Mbeya, respectively were positively accept it as appropriate intrinsic cue. This indicator is not accepted by $29.8 \%$ and $18.4 \%$ of the visited customers in Dar es Salaam and Mbeya, respectively. The general responses of the consumers on beef appearances in beef are not evenly distributed due to the observable variation of consumers in the visited cities. Other literature support this study appearance was used as one of the main beef quality determination indicators for fresh meat exposed for retail sale. Additionally, during evaluation, consumers who preferred beef as per marbling were also mentioned appearance as the main determinant for beef quality. It is also indicated that, beef appearance is used as one of the attributes in beef purchasing by consumers during the study of assessing the beef consumer preferences in Ethiopia. As it has been indicated, visual appearance of retail beef influence consumer purchases. Furthermore, this parameter is described as the determinant for beef quality that is positively accepted by many consumers.

\subsection{The Influence of Fat in Beef Quality Determination}

Fat content in retail beef is noted as one of the main influences of for determination of beef suitability. This presentation assumes fat content as the only available quality cue to be assessed by consumers in meat retailing shops. The applicability of fat content as determinant of quality in mleat retailing premises is presented based on the consumers' responses on the Likert scales on its applicability as judgment criteria. The results are arranged in clustered columns as percentage of consumers' responses against the categorized Likert scales in Figure 14. 


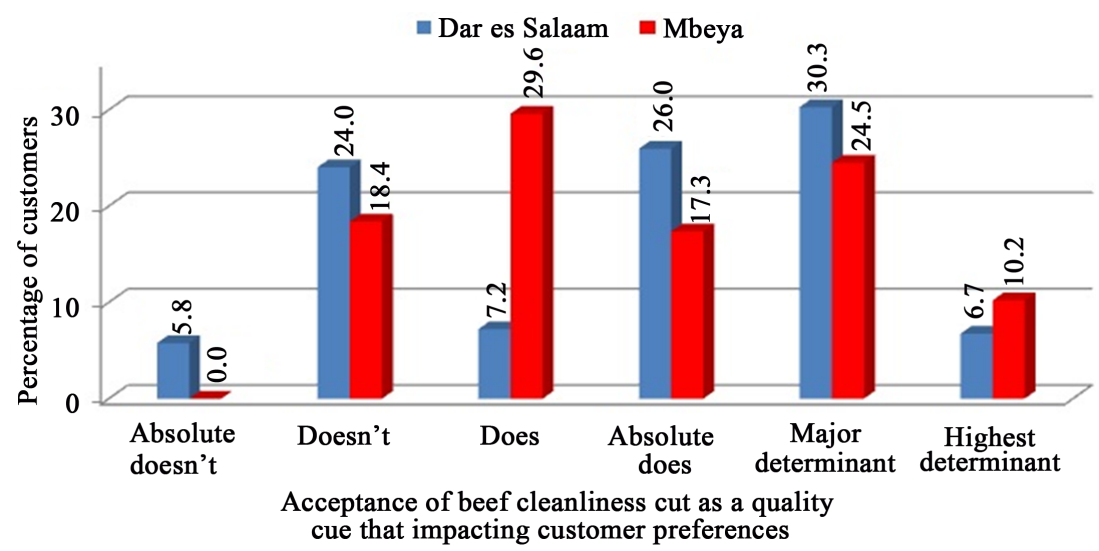

Figure 13. Likert Distribution of consumer responses on beef appearance as quality attribute cue influencing their preferences on beef $(N=208$ for Dar es Salaam and $N=98$ for Mbeya).

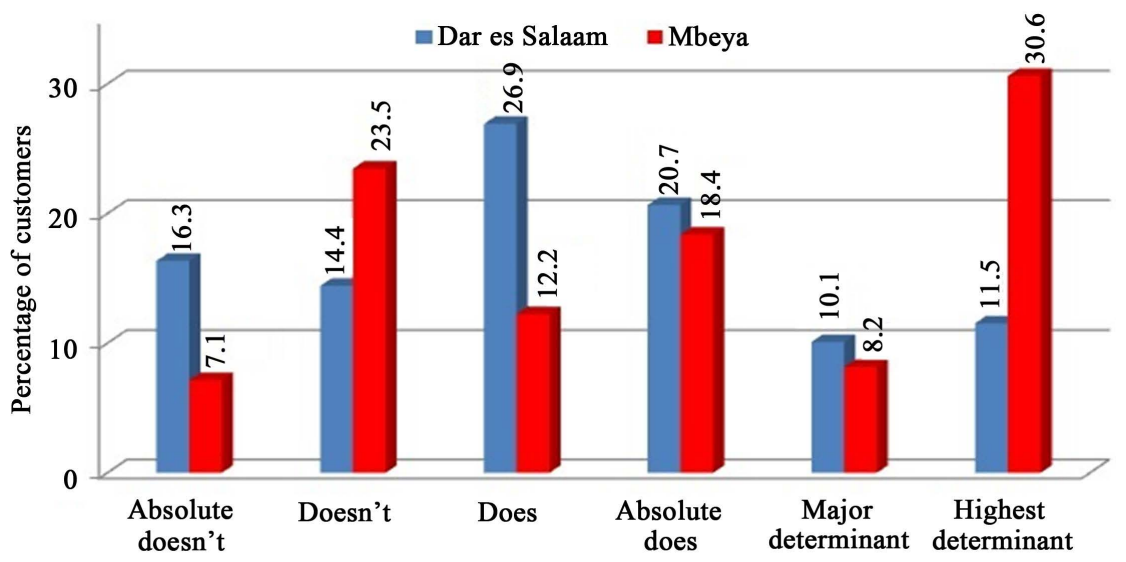

Acceptance of beef fat as a quality cue that impacting customer preferences

Figure 14. Distribution of consumer responses on the influence of fat on their preferences $(N=208$ for Dar es Salaam and $N=98$ for Mbeya).

Preference on the retail beef is presented based on fat content during which, about $69 \%$ of consumers in each of the visited city were positively accept it as appropriate intrinsic cue. Fat content on the other hand is not accepted by $31 \%$ of the customers from each of the visited city. The general responses of the consumers on fat in beef are not evenly distributed due to the observable variation particularly on absolutely rejection and considering fat as the highest determinant in both cities. This is also indicated in literature [47], where visible fat was used as one of the main criterion for grouping the University meat consumers into three main preference groups, i.e., lean meat (42.2\%), moderate fat (18.4\%) and meat with fat (39.5\%). Society classification based on fat preferences in beef was also observed in the study conducted in 183 villages in Addis Ababa, Ethiopia where the relative dislike for high fat beef was higher among higher income households. On the other hand the findings on the assessed influence of consumers characteristics on the choice of beef quality attributes in Tanzania revealed that fat is the only eating attribute that is favored by consumers [26]. 


\subsection{The Influence of Certification in Beef Quality Determination}

Fat content in retail beef is noted as one of the main influences of for determination of beef suitability. This presentation assumes fat content as the only available quality cue to be assessed by consumers in meat retailing shops. The applicability of fat content as determinant of quality in meat retailing premises is presented based on the consumers' responses on the Likert scales on its applicability as judgment criteria. The results are arranged in clustered columns as percentage of consumers' responses against the categorized Likert scales as indicated in Figure 15.

Preference on the retail beef is presented based on certification during which, $60.7 \%$ and $65.3 \%$ of consumers in Dar es Salaam and Mbeya were positively accept it as appropriate indicator. Retail and beef certification on the other hand is not accepted by $39.5 \%$ and $34.2 \%$ of the customers in Dares Salaam and Mbeya. Generally, the consumer variation on responses for certification as quality determinant is not high due to the observable range of about $5 \%$. The finding in this research is parallel with literature that indicated non conformances in beef retailing, during which more than half of the surveyed selling points were operated without certification [12].

\subsection{Statistical Evaluation of Data from Primary Sources}

Analytical results with respect to the reliability of customers' responses on the assessed beef quality attribute cues in Dar es Salaam and Mbeya were summarized in ANOVA Table as shown in Table 6.

With respect to the first hypothesis the output shows that $F=133.8(p<2.5 \times$ $\left.10^{-50}\right)$ for Mbeya and $F=91.5\left(p<2.8 \times 10^{-75}\right)$ for Dar es Salaam indicating that we should clearly reject the null hypothesis that beef quality cues collectively have no effect on the decision made during beef quality determination in retailing shops. This situation that is also denoted as $\left(\beta_{i} \neq \beta_{j}\right)$ as indicated in Table 7 proves that each of the beef quality cues has influence on the other in multiple regression analysis. For example, the findings show that the beef quality cue

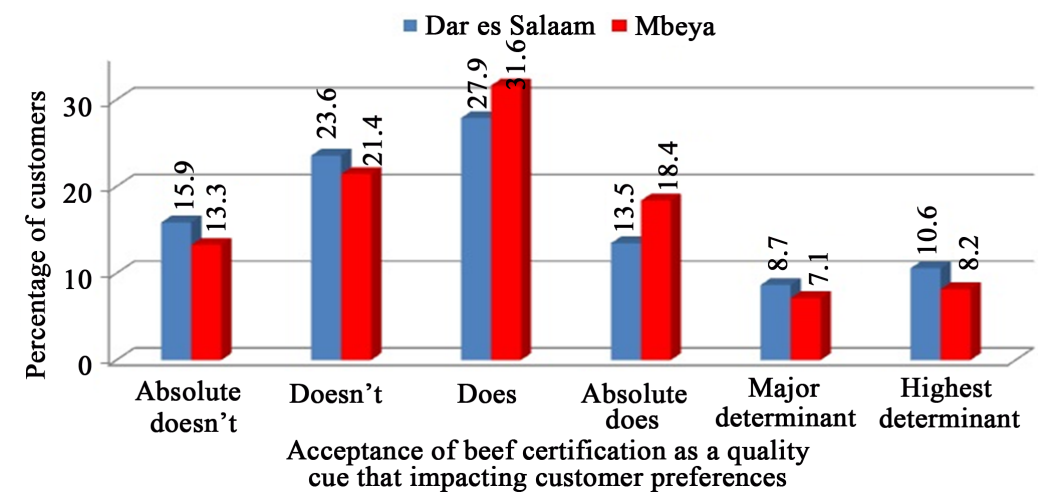

Figure 15. Distribution of consumer responses on certification as a beef quality attribute cue influencing their preferences in the beef retailing shops $(N=208$ for Dar es Salaam and $N=98$ for Mbeya). 
Table 6. Summarized results of ANOVA indicating degree of freedom (df), sum of squares (ss), means of squares (ms), test statistics (F) (N = 208 for Dar es Salaam and 98 for Mbeya).

\begin{tabular}{ccccccc}
\hline City & & $d f$ & $s s$ & $m s$ & $F$ & Significance $F$ \\
\hline \multirow{3}{*}{ Mbeya } & Regression & 13 & 64.9 & 5.0 & & \\
& Residual & 84 & 3.1 & 0.04 & 133.8 & $2.5 \times 10^{-50}$ \\
& Total & 97 & 68.0 & & & \\
\multirow{3}{*}{ Dar es salaam } & Regression & 13 & 105.3 & 8.1 & & \\
& Residual & 194 & 17.2 & 0.1 & 91.5 & $2.8 \times 10^{-75}$ \\
& Total & 207 & 122.4 & & & \\
\hline
\end{tabular}

Table 7. (a) Coefficients observed after regression analysis in Dar es Salaam $(\mathrm{N}=208)$; (b) Coefficients observed after regression analysis in Mbeya $(N=98)$.

(a)

\begin{tabular}{ccccc}
\hline Attribute & Coefficient $\left(\beta_{i}\right)$ & Standard error & $t$ statistics & $p$-value \\
\hline Intercept & 0.130 & 0.117 & 1.113 & 0.267 \\
Personal relation (seller and customer) & 0.016 & 0.015 & 1.057 & 0.292 \\
Price & 0.167 & 0.025 & 6.730 & $<0.001$ \\
Branding (packaging) & 0.017 & 0.024 & 0.721 & 0.472 \\
Freshness & 0.081 & 0.022 & 3.615 & $<0.001$ \\
Marbling & 0.098 & 0.029 & 3.337 & 0.001 \\
Beef presentation (type of cut) & 0.085 & 0.024 & 3.484 & 0.001 \\
Beef color & 0.099 & 0.023 & 4.282 & $<0.001$ \\
Fat content & -0.007 & 0.014 & -0.496 & 0.624 \\
Butcher's location & -0.010 & 0.021 & -0.463 & 0.644 \\
Advertisement (promotion) & -0.014 & 0.015 & -0.918 & 0.360 \\
Beef cleanliness & -0.036 & 0.023 & -1.553 & 0.122 \\
Beef selling certification & 0.005 & 0.014 & 0.334 & 0.739 \\
Smell (aroma) & 0.004 & 0.014 & 0.284 & 0.777 \\
\hline
\end{tabular}

(b)

\begin{tabular}{ccccc}
\hline Attribute & Coefficient & Standard error & $t$ statistics & $p$-value \\
\hline Intercept & 0.310 & 0.097 & 3.210 & 0.002 \\
Personal relation (seller and customer) & 0.119 & 0.079 & 1.515 & 0.134 \\
Price & 0.190 & 0.099 & 1.910 & 0.050 \\
Branding (packaging) & -0.018 & 0.013 & -1.317 & 0.191 \\
Freshness & -0.137 & 0.075 & -1.817 & 0.073 \\
Marbling & 0.079 & 0.039 & 2.008 & 0.048 \\
Beef presentation (type of cut) & 0.026 & 0.015 & 1.792 & 0.077 \\
Beef color & 0.129 & 0.047 & 2.723 & 0.008 \\
Fat content & 0.118 & 0.021 & 5.548 & $<0.001$ \\
Butcher's location & 0.104 & 0.034 & 3.042 & 0.003 \\
Advertisement (promotion) & 0.039 & 0.030 & 1.335 & 0.186 \\
Beef cleanliness & -0.104 & 0.032 & -3.251 & 0.002 \\
Beef selling certification & -0.043 & 0.053 & -0.826 & 0.411 \\
Smell (aroma) & -0.065 & 0.093 & -0.697 & 0.488 \\
\hline
\end{tabular}


marbling in Dar es Salaam is significant controlling for the variable beef presentation $(p=0.001)$, as is beef presentation controlling for the variable marbling ( $p$ $=0.001)$.

Table 7 was also presents results based on the second hypothesis, on the correlation between customers' responses on quality cues that impacting their respective preference on beef and their respective choice on the photos of standard graded beef.

Looking at individual tests in Table 7(a), five beef quality cues, i.e., price of beef $(\beta=0.167, p<0.005)$, beef color $(\beta=0.099, p<0.001)$, beef presentation (type of cut) $(\beta=0.085, p=0.001)$, Freshness $(\beta=0.081, p<0.001)$ and marbling ( $\beta=0.098, p=0.001)$ have significant influence on the consumers' responses on the displayed photo of beef. Other parameters have not significant influence since they have larger $p$ - values than 0.05 as recommended for individual tests.

The Table 7(b) shows price of beef $(\beta=0.190, p=0.05)$, beef color $(\beta=0.129$, $p=0.008)$, type of cut $(\beta=0.097, p<0.005)$, beef cleanliness $(\beta=0.074, p<$ $0.005)$, marbling $(\beta=0.079, p=0.048)$, butcher's location $(\beta=0.104, p<0.005)$ and fat content $(\beta=0.118, p<0.001)$ have significant influence on the responses on the displayed photo of beef in retailing shops. On the other parameters are not significant, implying that the choice of beef do not depend on these parameters.

The data in Table 8 was further indicated that the model is reliable for the intended use as the adjusted squares were $0.850\left(R^{2}=860\right.$, standard error $\left.=0.298\right)$ and $0.947\left(R^{2}=954\right.$, standard error $\left.=0.198\right)$ for Dar es Salaam $(N=208)$ and Mbeya $(N=98)$, respectively.

\subsection{Comparison of the Consumer Preferences on Beef Quality Attribute Cues}

Results with respect to the third hypothesis in this study that compared the surveyed cities with respect to customers' response on beef quality cues against the portrayed photo of beef are presented in Figure 16. It was indicated that all the assessed quality cues were positively accepted as the factors that influence consumers' preferences at more than $50 \%$, with smell (aroma) being the lowest accepted parameter in the cities. In addition to that, all the assessed beef quality

Table 8. Regression Table indicating the summary output of correlation between the Dar es Salaam consumers' responses on beef in the displayed guide and their respective responses on the beef quality indicators $(N=208)$.

\begin{tabular}{ccc}
\hline & Regression Statistics & \\
\hline City & Dar es Salaam & Mbeya \\
\hline $\mathrm{R}^{2}$ & 0.860 & 0.954 \\
Adjusted R & 0.850 & 0.947 \\
Standard error & 0.298 & 0.193 \\
Number of observations & 208 & 98
\end{tabular}




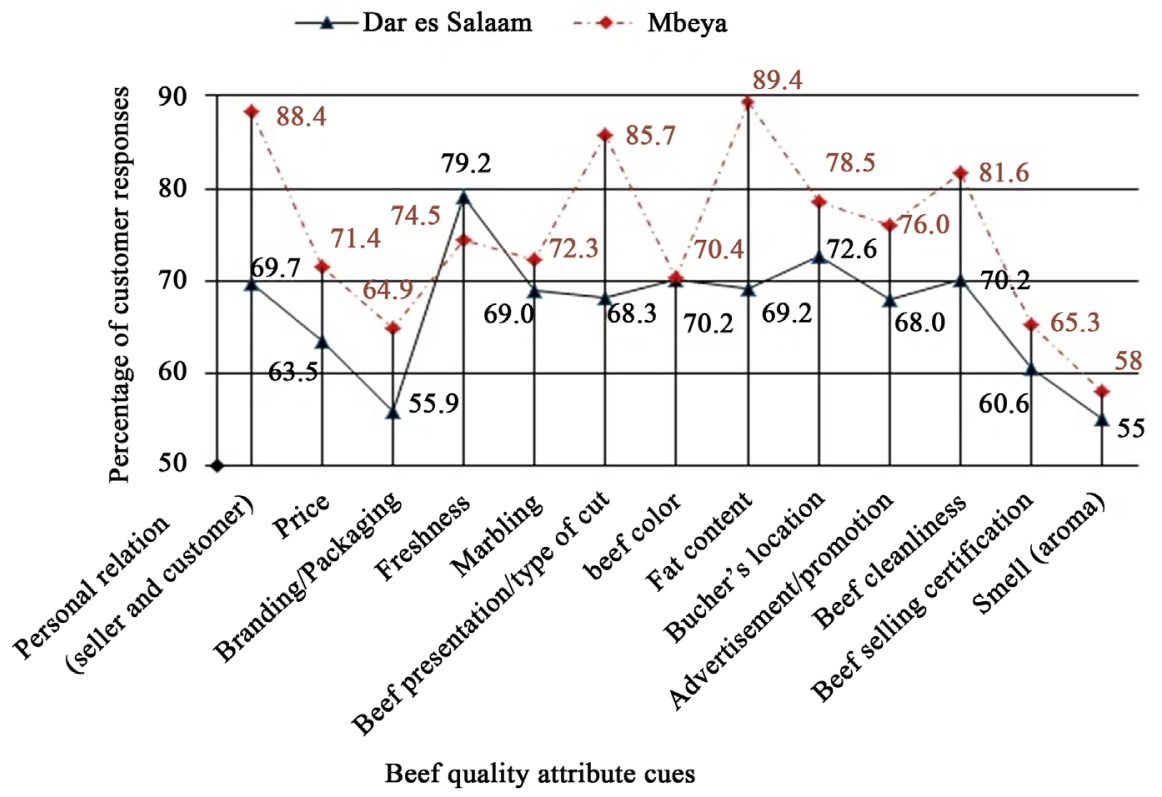

Figure 16. Customers who indicated that the quality attribute cues have an influence on their preferences against the portrayed photo of beef.

cues, except freshness were responded as appropriate beef quality cues that impacting the preferences of customers in Mbeya at higher rate than in Dar es Salaam.

It was further observed that, the top three highest pointed quality cues were fat content (89.4\%), personal relation (88.4\%) and beef presentation (type of cut) (85.7\%) that were responded in Mbeya. On the other hand, the top three scored quality cues in Dar es Salaam were freshness (79.2\%), butcher's location (72.6\%) and beef cleanliness (70.2\%) together with beef color (70.2\%). Similar to this study, butcher's location was also reported in literature [3] [36] as one of the strong quality cues that impacting customer preferences on beef. This was observed in Gauteng Province, South Africa together with Nairobi and Isiolo counties in Kenya, where customers in lower and middle class areas prefers meat in retail outlets with in lower food safety and quality standard.

\section{Conclusion and Remarks}

The five topmost documented beef quality cues among all parameters in the reviewed 29 publications which impact consumer preferences are the tenderness, price, juiciness, breed's information and fat content. The three highest ranked beef quality cues in each of the quality attributes were observed to be price, fat content and smell (aroma) in search attribute; breed's information, nutrition and chemical residues in credence attribute; and tenderness, juiciness and taste in experience quality, respectively. While price, juiciness and breed's information the highest ranked quality cues across the search, experience and credence quality attributes, Branding (packaging), flavor and traditional image were observed to be the lowest ranked beef quality cues. 
Based on the results, it can be concluded that there is dissimilarity of preferences as select and choice were separately identified as the best among the displayed pieces of beef by $42.9 \%$ and $40.4 \%$ of the visited consumers in Mbeya and Dar es Salaam, respectively. The choice and prime in the portrayed photo were similarly pointed by $28.6 \%$ of the consumers in the visited meat retailing shops at Mbeya. About $36.6 \%$ and $28.5 \%$ of visited consumers in Dar es Salaam and Mbeya, respectively, did not positively accept the strength of price as a reliable extrinsic cue. While beef price was absolutely not accepted by $27.9 \%$ and $12.2 \%$ of customers in Dar es Salaam and Mbeya, respectively, more than $65.3 \%$ of the consumers accepted and among them, 13.3\% and 4.3\% accepted it as the highest determinant in Mbeya and Dar es Salaam, respectively.

While $72.7 \%$ and $73.5 \%$ of customers in Dar es Salaam and Mbeya, respectively, positively accepted butcher's location as beef quality cue which impacting their preferences on beef, about $27.5 \%$ and $26.5 \%$ in the respective cities did not. On the other hand, Butcher's location, was both absolutely rejected and very positively accepted in Mbeya as appropriate beef determinant indicator by $7.1 \%$ and $12.2 \%$ of the visited consumers, respectively.

Personal relation between sellers and customers was absolutely not accepted as among quality cues that impacts their respective preference on beef by $30.3 \%$ and $30.7 \%$ of customers in Dar es Salaam and Mbeya, respectively. About 70\% of customers in Mbeya and Dar es Salaam, positively accepted color of beef as the one of the quality cues that impact their respective preferences. Moreover, about 7.7\% of the consumers in Dar es Salaam absolutely rejected location as a quality cue influencing their preferences on beef.

The type of cut of beef is absolutely not accepted as an impacting beef quality cue by $31.7 \%$ and $14.3 \%$ of the visited customers in Dar es Salaam and Mbeya, respectively. The general responses of the consumers on type of cut in beef are not uniform due to the noticeable variation of consumers responses especially at doesn't (3.1\% for Mbeya and 24.0\% for Dar es Salaam); "Major determinant" (28.4\% for Dar es Salaam and 3.1\% for Mbeya; and highest determinant (11.1\% for Dar es Salaam and 35.7\% for Mbeya). Beef cleanliness was not accepted by $29.8 \%$ and $18.4 \%$ of the visited customers in Dar es Salaam and Mbeya, respectively, while the general responses of the consumers on beef appearances in beef are not evenly distributed especially at absolutely rejection (5.8\% for Dar es Salaam and $0.0 \%$ for Mbeya).

Preference on the retail beef based on fat content indicated that about $69 \%$ of consumers in each of the visited cities positively accept it as quality cue that impact their preferences. The general responses of the consumers on fat in beef were not evenly distributed due to the observable variations, particularly on both absolutely rejection (16.3\% for Dar es Salaam and 5.1\% for Mbeya) and highest determinant (11.5\% for Mbeya and 30.6\% for Dar es Salaam).

Certification was positively accepted as appropriate beef quality cue by $60.7 \%$ and $65.3 \%$ of consumers in Dar es Salaam and Mbeya. However, the consumer variation on responses for certification as quality determinant is not high due to 
the observable range of about $5 \%$ across all the levels agreement from absolute doesn't to the highest determinant.

Beef cleanliness and type of cut were positively responded as appropriate cues that impacting customers' preference by high percentage of customers in Mbeya at $85.7 \%$ and $82.6 \%$, respectively, than in Dar es Salaam. While all of the assessed quality cues were positively accepted as the factors that influence consumers' preferences at more than $50 \%$, beef certification was the lowest accepted parameter in the surveyed cities.

Generally, all the assessed beef quality cues were positively accepted as appropriate factors that influence consumers' preferences at more than $50 \%$, with smell (aroma) being the lowest accepted parameter in the cities. They were collectively affect decision made during beef quality determination in retailing shops with price, color, presentation, freshness and marbling of beef noted to have significant contribution to the consumers' choice in both cities.

\section{Conflicts of Interest}

The authors declare no conflicts of interest regarding the publication of this paper.

\section{References}

[1] Acebrón, L.B. and Dopico, D.C. (2000) The Importance of Intrinsic and Extrinsic Cues to Expected and Experienced Quality: An Empirical Application for Beef. Food Quality and Preference, 11, 229-238. https://doi.org/10.1016/S0950-3293(99)00059-2

[2] Schröder, M.J.A. and McEachrn, M.G. (2002) ISO 9001 as an Audit Frame for Integrated Quality Management in Meat Supply Chains: The Example of Scotish Beef. Managerial Audit Journal, 17, 79-85. https://doi.org/10.1108/02686900210412289

[3] Vermeulen, H., Schönfeldt, H.C. and Pretorius, B. (2015) A Consumer Perspective of the South African Red Meat Classification System. Southern African Journal of Animal Science, 45, 339-354.

[4] Garvin, A.D. (1984) What Does "Product Quality” Really Mean? Sloan Management Review, 26, 25-43.

[5] Żakowska-Biemans, S., Pieniak, Z., Gutkowska, K., Wierzbicki, J., Cieszyńska, K., Sajdakowska, M. and Kosicka-Gębsca, M. (2017) Beef Consume Segment Profiles Based on Information Source Usage. Meat Science, 124, 105-113. https://doi.org/10.1016/j.meatsci.2016.11.001

[6] Becker, T. (2000) Consumer Perception of Fresh Meat Quality: A Framework for Analysis. British Food Journal, 102, 158-176. https://doi.org/10.1108/00070700010371707

[7] Banović, M., Grunert, K.G., Barreira, M.M. and Fontes, M.A. (2009) Quality Perception at the Point of Purchase: A Study from Portugal. Food Quality and Preference, 20, 335-342. https://doi.org/10.1016/j.foodqual.2009.02.009

[8] Rosegrant, M.W., Leach, N. and Gerpacio, V. (1999) Alternative Futures for World Cereal and Meat Consumption. Proceedings of the Nutrition Society, 58, 219-234. https://doi.org/10.1017/S0029665199000312

[9] Teye, G.A. and Okutu, I. (2009) Effect of Ageing under Tropical Conditions on the 
Eating Qualities of Beef. African Journal of Food Agriculture Nutrition and Development, 9, 1901-1913.

[10] Font-i-Furnols, M. and Guerrero, L. (2014) Consumer Preference, Behavior and Perception about Meat and Meat Products: An Overview. Meat Science, 98, 361-371. https://doi.org/10.1016/j.meatsci.2014.06.025

[11] Kotsanopoulos, K.V. and Arvanitoyannis, I.S. (2017) The Role of Auditing, Food Safety, and Food Quality Standards in the Food Industry: A Review. Comprehensive Reviews in Food Science and Food Safety, 16, 760-775. https://doi.org/10.1111/1541-4337.12293

[12] Adzitey, F. (2011) Mini Review Effect of Pre-Slaughter Animal Handling on Carcass and Meat Quality Yield. International Food Research Journal, 18, 485-491.

[13] Bernués, A., Olaizola, A. and Corcoran, K. (2003) Extrinsic Attributes of Red Meat as Indicator of Quality in Europe: An Application for Market Segmentation. Food Quality and Preference, 14, 265-276. https://doi.org/10.1016/S0950-3293(02)00085-X

[14] Henchioni, M.M., McCarthy, M. and Resconi, V.C. (2017) Beef Quality Attributes: A Systematic Review of Consumer Perspectives. Meat Science, 128, 1-7. https://doi.org/10.1016/j.meatsci.2017.01.006

[15] Cross, H.R. and Savell, J.W. (1994) What Do We Need for a Value-Based Beef Marketing System? Meat Science, 36, 19-27. https://doi.org/10.1016/0309-1740(94)90030-2

[16] Polkinghorne, R.J. and Thompson, J.M. (2010) Meat Standard and Grading a World View. Meat Science, 86, 227-235. https://doi.org/10.1016/j.meatsci.2010.05.010

[17] Grunert, K.L., Bredahl, L. and Brunsø, K. (2004) Consumer Perception of Meat Quality and Implications for Product Development in the Meat Sector: A Review. Meat Science, 66, 259-272. https://doi.org/10.1016/S0309-1740(03)00130-X

[18] Bevan, N. (1995) Usability Is Quality of Use. Advances in Human Factors/Ergonomics, 20, 349-354.

[19] Bevan, N. and Macleod, M. (1994) Usability Measurement in Context. Behaviour and Information Technology, 13, 132-145. https://doi.org/10.1080/01449299408914592

[20] Bevan, N. (1995) Measuring Usability as Quality of Use. Software Quality Journal, 4, 115-150. https://doi.org/10.1007/BF00402715

[21] Nam, K.-C., Jo, C. and Lee, M. (2010) Review: Meat Products and Consumption Culture in the East. Meat Science, 86, 95-102. https://doi.org/10.1016/j.meatsci.2010.04.026

[22] Troy, J.D. and Kerry, J.P. (2010) Consumer Perception and the Role of Science in Meat Industry. Meat Science, 86, 214-226. https://doi.org/10.1016/j.meatsci.2010.05.009

[23] Grunert, K.G. (2005) Food Quality and Safety: Consumer Perception and Demand. European Review of Agricultural Economics, 32, 369-391. https://doi.org/10.1093/eurrag/jbi011

[24] Cagney, C., Crowley, H., Duffy, G., Sheridan, J.J., Brien, S.O., Carney, E., Anderson, W., McDowell, D.A., Blair, I.S. and Bishop, R.H. (2004) Prevalence and Numbers of Escherichia coli O157:H7 in Minced Beef and Beef Burgers from Butcher Shops and Supermarkets in the Republic of Ireland. Food Microbiology, 21, 203-212. https://doi.org/10.1016/S0740-0020(03)00052-2

[25] China, C.R. and Ndaro, M.S. (2016) A Review on Tanzanian Leather Value Chain 
Status. African Journal of Science and Research, 5, 55-60.

[26] Nandonde, S.W., Msuya, E. and Mtenga, L.A. (2013) Assessment of the Influence of Consumer Characteristics on the Choice of Beef Quality Attributes in Tanzania: An Experimental Economic Approach. Journal of Agricultural Economics and Development, 2, 111-119.

[27] Gilbert, C.L., Christiaensen, L. and Kaminski, J. (2017) Food Price Seasonality in Africa: Measurement and Extent. Food Policy, 67, 119-132. https://doi.org/10.1016/j.foodpol.2016.09.016

[28] Khan, K.S., Kunz, R., Kleijnen, J. and Antes, G. (2003) Five Steps to Conducting a Systematic Review. Journal of the Royal Society of Medicine, 96, 118-121. https://doi.org/10.1177/014107680309600304

[29] Salmond, S.W. (2013) Finding Evidence to Support Evidence-Based Practice. Orthopaedic Nursing, 32, 16-22.

[30] Mitra, D. and Golder, P.N. (2006) How Does Objective Quality Affect Perceived Quality? Short Term Effects, Long-Term Effects, and Asymmetries. Marketing Science, 25, 230-247. https://doi.org/10.1287/mksc.1050.0175

[31] Schor, A., Cossu, M.E., Picallo, A., Ferrer, J.M., Naón, J.J.G. and Colombatto, D. (2008) Nutritional and Eating Quality of Argentinean Beef: A Review. Meat Science, 79, 408-422. https://doi.org/10.1016/j.meatsci.2007.10.011

[32] Hocquette, J.F, Botreau, R., Picard, B., Jacquet, A., Pethick D.W. and Scollan, N.D. (2012) Opportunities for Manipulating Beef Quality: A Review. Meat Science, 92, 197-209. https://doi.org/10.1016/j.meatsci.2012.04.007

[33] Aalhus, J.L., Lopez-Campos, O., Prieto, N., Rodas-Gonza, A., Dugan, M.E.R., Uttaro, B. and Juárez, M. (2014) Review: Canadian Beef Grading Opportunities to Identify Carcass and Meat Quality Traits Valued by Consumers. Canadian Journal of Animal Science, 94, 545-556. https://doi.org/10.4141/cjas-2014-038

[34] Perez, L., Boland, M. and Schroeder, T. (2003) Country of Origin Labeling for Uruguayan Beef. International Food and Agribusiness Management Review, 6, 1-12.

[35] Telligman, A.L., Worosz, M.R. and Bratcher, C.L. (2017) "Local" as an Indicator of Beef Quality: An Exploratory Study of Rural Consumers in the Southern U.S. Food Quality and Preference, 57, 41-53. https://doi.org/10.1016/j.foodqual.2016.11.001

[36] Chepkemoi, S., Lamuka, P.O., Abong, G.O. and Matufari, J. (2015) Sanitation and Hygiene Meat Handling Practices in Small and Medium Enterprise Butcheries in Kenya-Case Study of Nairobi and Isiolo Counties. Internet Journal of Food Safety, 17, 64-74.

[37] Birhamu, S. and Menda, S. (2017) Hygienic Handling and Processing of Raw Beef Meat at Slaughter Houses and Meat Stalls in Gojjam Area, Ethiopia. International Journal of Veterinary Health Science and Research, 5, 213-218.

[38] Ntanga, P.D., Mdegela, R.H. and Nonga, H.E. (2014) Assessment of Beef Microbial Contamination at Abattoir and Retail Meat Shops in Morogoro Municipality, Tanzania. Tanzania Veterinary Journal, 29, 53-61.

[39] Rani, Z.T., Hugo, A., Hugo, C.J., Vimiso, P. and Muchenje, V. (2017) Effect of Post-Slaughter Handling during Distribution on Microbiological Quality and Safety of Meat in the Formal and Informal Sectors of South Africa: A Review. South African Journal of Animal Science, 47, 255-267. https://doi.org/10.4314/sajas.v47i3.2

[40] Grunert, K.G. (2011) Sustainability in the Food Sector: A Consumer Behaviors Perspective. International Journal of Food System Dynamics, 2, 207-218.

[41] Zeithaml, V.A. (1988) Consumer Perceptions of Price, Quality, and Value, a Means 
End-Model and Synthesis of Evidence. Journal of Marketing, 52, 2-22. https://doi.org/10.1177/002224298805200302

[42] Sinha, P.K. and Banerjee, A. (2004) Store Choice Behaviour in Evolving Market. International Journal of Retail and Distribution Management, 32, 482-494.

[43] Goldman, A. and Hino, H. (2005) Supermarkets in China: The Case of Shanghai. The International Review of Retail, Distribution and Consumer Research, 10, 1-21. https://doi.org/10.1080/095939600342370

[44] Chamhuri, N. and Batt, P.J. (2013) Exploring the Factors Influencing Consumers' Choice of Retail Store When Purchasing Fresh Meat in Malaysia. International Food and Agribusiness Management Review, 16, 99-123.

[45] Strydom, P.E., Frylinck, L., van Heerden, S.M., Hope-Jones, M., Hugo, A., Webb, E.C., Moholisa, E., Liebenberg, B.E. and Sehoole, O.C. (2015) Sources of Variation in Quality of South African Beef: Case Studies in Relation to the Red Meat Classification System. South African Journal of Animal Science, 45, 289-301.

[46] Shackelford, S.D., Wheelers, T.L., Meade, M.K., Reagan, J.O., Byrnes, B.L. and Koohmaraie, M. (2001) Consumer Impressions of Tender Select Beef. Journal of Animal Science, 79, 2605-2614. https://doi.org/10.2527/2001.79102605x

[47] Boleman, S.J., Boleman, S.L., Miller, R.K., Taylor, J.F., Cross, H.R., Wheeler, T.L., Koohmaraie, M., Shackelford, S.D., Miller, M.F., West, R.L., Johnson, D.D. and Savell, J.W. (1997) Consumer Evaluation of Beef of Known Categories of Tenderness. Journal of Animal Science, 75, 1521-1524. https://doi.org/10.2527/1997.7561521x 